\title{
Modelling Global Nickel Mining, Supply, Recycling, Stocks-in-Use and Price Under Different Resources and Demand Assumptions for 1850-2200
}

\author{
Anna Hulda Olafsdottir ${ }^{1}$ (D) Harald Ulrik Sverdrup ${ }^{2}$ (D) \\ Published online: 26 January 2021 \\ (C) The Author(s) 2021
}

\begin{abstract}
The long-term supply of nickel to society was assessed with the WORLD7 model for the global nickel cycle, using new estimates of nickel reserves and resources, indicating that the best estimate of the ultimately recoverable resources for nickel is in the range of 650-720 million ton. This is significantly larger than earlier estimates. The extractable amounts were stratified by extraction cost and ore grade in the model, making them extractable only after price increases and cost reductions. The model simulated extraction, supply, ore grades, and market prices. The assessment predicts future scarcity and supply problems after 2100 for nickel. The model reconstructs observed extraction, supply and market prices for the period 1850-2020, and is used to simulate development for the period 2020-2200. The quality of nickel ore has decreased significantly from 1850 to 2020 and will continue to do so in the future according to the simulated predictions from the WORLD7 model. For nickel, extraction rates are suggested to reach their maximum value in 2050, and that most primary nickel resources will have been exhausted by 2130 . After 2100 , the supply per capita for nickel will decline towards exhaustion if business-as-usual is continuing. This will be manifested as reduced supply and increased prices. The peak year can be delayed by a maximum of 100 years if recycling rates are improved significantly and long before scarcity is visible.
\end{abstract}

Keywords WORLD7 · Systems dynamics · Nickel · Sustainability · Nickel market price

\section{Introduction}

Nickel is a key metal for manufacturing stainless steel and other alloys with unique properties used in new technologies. It is an essential component in new types of rechargeable batteries and an essential metal for making chemical catalysts. It is frequently used in plating. Nickel is mined both at the surface and in deep underground mining. It follows platinum group metals deposits and these mines sometimes reach down to $4 \mathrm{~km}$ depth. Note that only metals of great value are mined

Harald Ulrik Sverdrup

harald.sverdrup@inn.no

Anna Hulda Olafsdottir annahulda@hi.is

1 Industrial Engineering, University of Iceland, Hjarðarhagi 2-6, IS-107, Reykjavik, Iceland

2 Gamification and Interactive Simulations (Gameschool), Norway Inland University of Applied Sciences, Holsetgaten 31,

2318 Hamar, Norway to such depths, only they are worth the cost of doing so and in itself, this shows the massive demand for nickel. Nickel is mined to great depths in South Africa, in Canada at Sudbury and nickel in central Siberia, in Russia. The issue of sustainable resource supply to society has been a serious concern since the book "Limits to growth" put the focus on these issues [1-3]. There have been many warnings over time for limits to resources availability [1-9]. Fully dynamic integrated system dynamics models do include the necessary elements of dynamics; market mechanisms, change in production rates, change in the population, change in recycling, and change in-use efficiency. For policy development purposes, systems modelling will have the necessary and required parts integrated.

\subsection{Earlier Dynamic Modelling Studies}

Earlier global systems dynamics model for the global system for nickel, involving systems feedbacks from market dynamics, extraction dynamics, market price mechanisms on supply and demand and simultaneously were not found. Daigo et al. [10] did material flow analysis of chromium and nickel for 
steel manufacture. The traditional econometric models lack stocks and generally lacks systems feedbacks, and they represent a very simplified representation of the global economic system [11-16]. The conventional mass flow models based on spreadsheets without feedbacks have been described by Giljum and Hubacek [17] and Giljum et al., [18], but they are not dynamic models in a sense that they do not include feedbacks like supply and demand effects on the market price, price feedback to demand, profit feedbacks on supply and further investments, price feedback on the recycling rate, cost feedback on a decline in profits and increased investment in technology for increased efficiency. The lack of feedbacks makes most of the earlier resource scarcity assessments of limited use for policy development and future planning.

\section{Scope and Objectives}

The scope of this paper is to use the WORLD7 model to assess the sustainability of the long-term nickel supply. The WORLD7 model is an integrated assessment model which will be outlined later. The aim is to give answers to the following questions based on the simulation outputs.

1. For the sustainability of nickel supply and the risks for any type of shortages or limitations, including:

- the evolution of the nickel resources based on the Base run case

- the evolution of the nickel resources based on variations in initial resource size and demand

- the supply per person per year estimates.

2. The price evolution.

\section{Methods}

Several methods were used for this study. The methodology used here is systems analysis as the standard tool for conceptualization and preparation for the building of a simulation code. The primary simulation tool is based on system dynamics modelling [19-22]. It is fundamental to understand that causal understanding is the model. Systems analysis produces causal loop diagrams (CLD) linking causes, effects, and feedbacks among linked processes in terms of causalities and flows [21]. Systems analysis was used to map the production, trade, and consumption system. The system resulting from the flow charts and the causal loop diagrams is then numerically solved using the STELLA ${ }^{\circledR}$ modelling environment. WORLD7 model, as the surrounding modelling platform, is a further development of the WORLD7model used earlier in similar studies.

Most of the process parameters have a physical significance and can be estimated based on measurements. For the resource estimates, the authors went through several survey reports and scientific literature, including several national and international reports from geological surveys. This study is focused on long-term aspects, i.e., with times longer than the most extended delay in the system, which is 60 years for steel that gets into constructions and more massive infrastructures. That implies that we need to be looking about 180-200 years into the future with the model.

All the runs have been based on a base run scenario run, business as usual, from 1900 to 2200 (called Base run in the figures). Business as usual here stands for continuing the policies of today, with no significant future change. The results were used to compare with historic data to check the performance of the model. A sensitivity runs were made to investigate how much the runs react to changes in resource size and demand.

In the following chapter, a description of the main methods, the data used, and validation methods are described in the following order: the methods used for resource estimation (Section 3.1), ore grade classification (Section 3.2), modelling methods (Section 3.3) including a description of the conceptual model behind the nickel submodule (Section 3.3.1), a description of the dynamics of the production and extraction based on how it is represented in the WORLD7 model (Section 3.3.2), the market model applied in the WORLD7 (Section 3.3.3), the data used for the nickel reserves and resources based on available data, assumptions and estimations.

\subsection{WORLD7}

A description of the conceptual model behind the nickel submodule is presented in this chapter. The WORLD7 model is a large model and has been published quite a lot. Further reading on it can be found in appendix. Figure 1 shows a highly aggregated (simplified) causal loop diagram (CLD) of the WORLD7 model showing how the energy resources and metal and materials resources interact and affect consumption and population. It is noted that the CLD is intentionally made as simple as possible, and in many cases, the links would need considerable disaggregation to show the causal relations represented in the WORLD7 model truly. This CLD is an attempt to capture some of the core links in the model. The figure shows six reinforcing loops. The loops are marked with numbers and appropriate letter, $\mathrm{R}$ for reinforcing loops and B for balancing loops. The balancing loops, balance the reinforcing loops (R) and slows them down. Looking at the reinforcing loops, the first one, (R1), also named the fertility growth loop goes from fertility rate through the population, more population means more demand resulting in more consumption and 
Fig. 1 An aggregated version of some of the feedback loops that affect the population variable

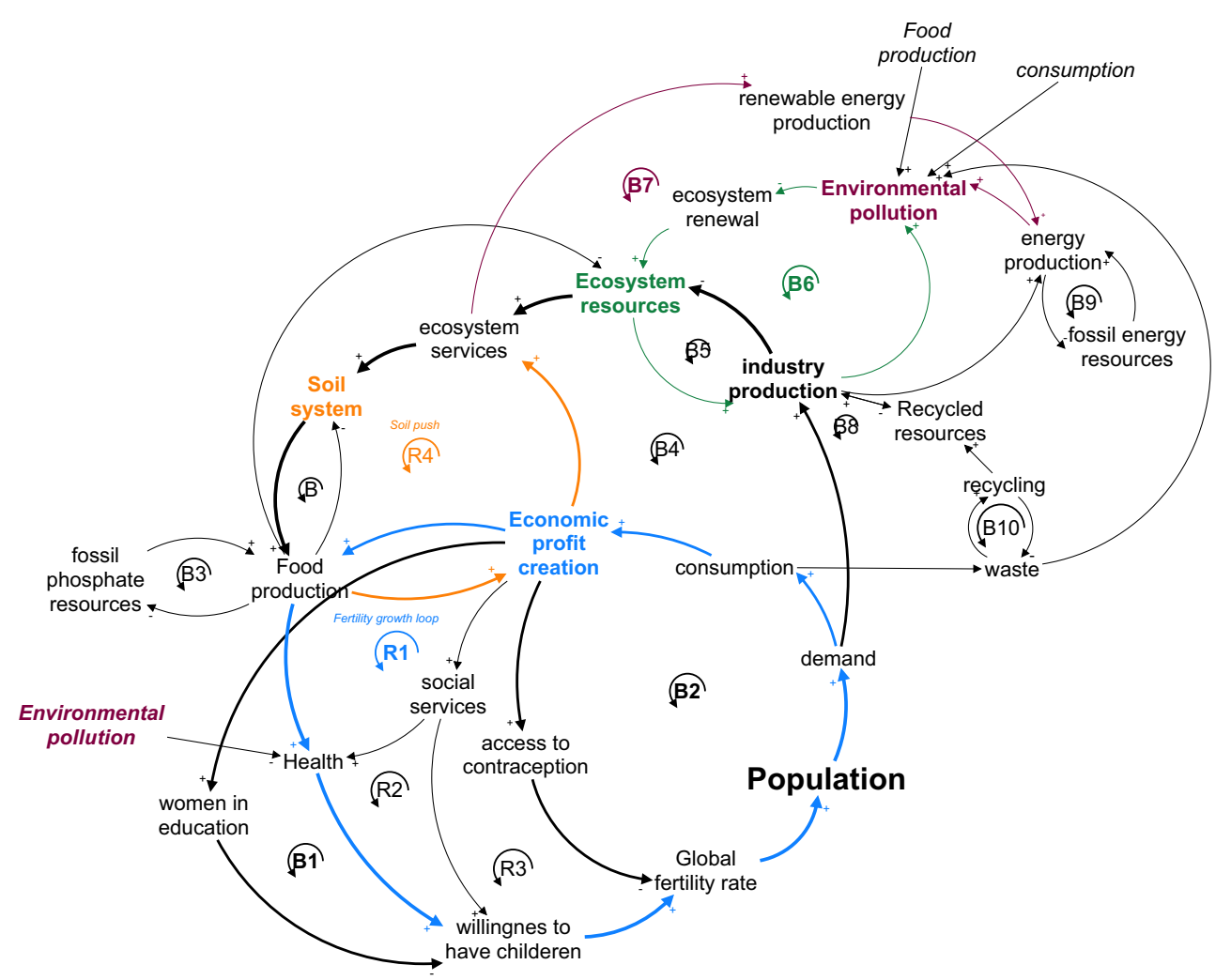

more economic profit creation that also has a positive effect on the food production and then health and willingness to have children. Then from the economic profit, we also have a yet another push from the social services through both health (R2) and willingness to have children (R3). Also, one that goes through the soil system, soil push, (R4) and food production that also gave positive feedback to the economic growth variable that gives the same push eventually to population. Then, we have several balancing loops to dampen the population growth, f.x. (B1) from the economic growth, we have a positive effect on the number of women in education that will actually decrease the willingness to have children and also more access to contraception that will have the same effect.

It is noted that the nickel module is a small part of the overall WORLD7 model. The WORLD7 model is based on the WORLD6 model [23], the main difference lies in the added number of sub-models in the WORLD7 model including transforming the sectorial based structure into modules in the STELLA software. Population size and GDP is generated internally in the WORLD7 model in the population and food sub-module [24]. The population size is used together with GDP for generating demand $[25,26]$. Note that the term recycling appears on both sides. There is an essential point to it that determines the amount of material possible to keep in the cycle. It expands the total flux going through the system, without demanding new primary material to be added. The larger the recycling, the less new pristine materials is required to keep the same volume in circulation. For any limited resource, this is a fundamental principle. For assessment of soft and hard physical scarcity, two metrics for indicating whether there is scarcity or not is suggested $[7,27]$ supply per person per year and stocks-in-use per person. Supply per person per year is serving maintenance of stocks-in-use, and the surplus over the maintenance will determine how much is left for growth or if there will be a material contraction. Stocks-inuse is a measure of the present utility of the resource. A decrease in stocks-in-use which is not paralleled by a substitute that increases will be an indicator of growth, steady-state or decline in the provision of service by that resource. Typically, society can deal with soft scarcity without massive disturbances. Sometimes, a hard scarcity may lead to the loss of technical capability. All of these have ramifications in society [28]. Supply is composed of both primary production, secondary extraction as a by-product of the production of other metals and recycling of used material. From a mass balance perspective, equation (1) emerges on the global scale;

Mined + Secondary production + Recycling

$=$ Accumulation in the system + Recycling + Losses (1)

In the WORLD7 model, nearly everything is internally connected through flows and causal links. It is based on global scale mass balances and does not yet distinguish individual 
countries. "Mined" is what is taken from the geological reserves, and there is no other net production of new metal into the system. "Secondary production" is metal derived from mining of other metals like copper [29], platinum group metals [26], cobalt [30], or molybdenum [32]. "Accumulated in the system" is stocks-in-use in society, and "Losses" is what is lost in such a way that it cannot be retrieved again, it leaves the system. "Recycling" refers to metals that are circulated in the system by recapturing them from waste and adding them back into the market. "Recycling" is present on both sides of the equation, increasing the internal flux. The primary net system input may remain low if the recycled fraction of losses is enormous. The need to mine becomes less when recycling is increased to keep the same amount in society.

\subsubsection{Methods for Resource Estimation}

For the resource estimates, the authors analyzed a large number of survey reports and scientific literature, including several national and international reports from geological surveys. The method has several steps:

1. Establish how much metal is present in the deposit and at what concentration.

2. Sort up the total resource in quality classes, based on extraction costs and process yields.

3. Establish the fraction of the present metal that will be ultimately recovered, based on ore grade cut-off limit and extraction yield estimates.

The resource estimates are put into resource evolution plots, where the estimates are plotted versus time. These plots allow the ultimately recoverable resources to be estimated $[25,26,29,30,31]$ Extraction cut-off is dependent on technology and degree of the repetitiveness of the extraction method. It is composed of different elements:

- Accessibility yield: The deposit may be suitable for mining but cannot be accessed. It may be under a city, a lake, the ocean, in a protected area, in a conflict zone or otherwise not be accessible. $\left(\mathrm{Y}_{\mathrm{A}}\right)$.

- Prospecting yield: Prospecting yield is the fraction of the hidden resource that will eventually be discovered and will get an extraction classification with an associated extraction cost, $\left(\mathrm{Y}_{\mathrm{P}}\right)$. The prospecting yield is difficult to get actual numbers, see Fig. 5 for a CLD explaining how prospecting is handled in the model. In the tables that follow later, a realistic suggestion is made for yield as a kind of expert opinion.

- Mining yield: Mining yield is a measurable and known entity and part of the mining preparatory engineering. It is the fraction of the ore deposit located in the deposit and classified as extractable in the past, the present or in the future that will be mechanically or chemically excavated from the geological deposit, $\left(\mathrm{Y}_{\mathrm{M}}\right)$.

- Extraction yield: Extraction yield is a known mining engineering design parameter. It is the fraction of the excavated rock that will become a substrate for refining, involving the cut-off grade $\left(\mathrm{Y}_{\mathrm{E}}\right)$.

- Refining yield: The fraction of the metal recovered from the refining substrate, $\left(Y_{R}\right)$. Refining yield is a known chemical engineering design parameter in refinery operations planning. Where the total yield will be:

$\mathrm{Y}=\mathrm{Y}_{\mathrm{A}} * \mathrm{Y}_{\mathrm{P}} * \mathrm{Y}_{\mathrm{E}} * \mathrm{Y}_{\mathrm{M}} * \mathrm{Y}_{\mathrm{R}}$

Note that these are some of the conditions and assumptions used: (1) the overall extraction yields from mountain to market tend to increase from low to higher over time, driven by increases in price that in turn drive technological improvements and better work methods; and (2) the extraction cut-off is dependent on technology, extraction costs, and the metal price at the time. Repetitive refining is used when the yield in a single step is low. The refining yield will be a function of the extractive efficiency when treating the ore shipped to the refinery, using a single step or repetitive processes. Extraction cut-off is dependent on technology and the degree of the repetitiveness of the extraction method.

Figure 2 gives examples of typical yields found in mining and extraction operations. The material contained below the cut-off grade is lost with rock waste. The refining yield is the fraction of the metal that gets into the refining process, that will show up as extracted metal available for sale at the very end. Rocks with a particular content are sought for and dugout.

The rocky ore material is refined using a combination of mechanical and chemical methods. "Gained in refining" concerning the content of the whole square is the

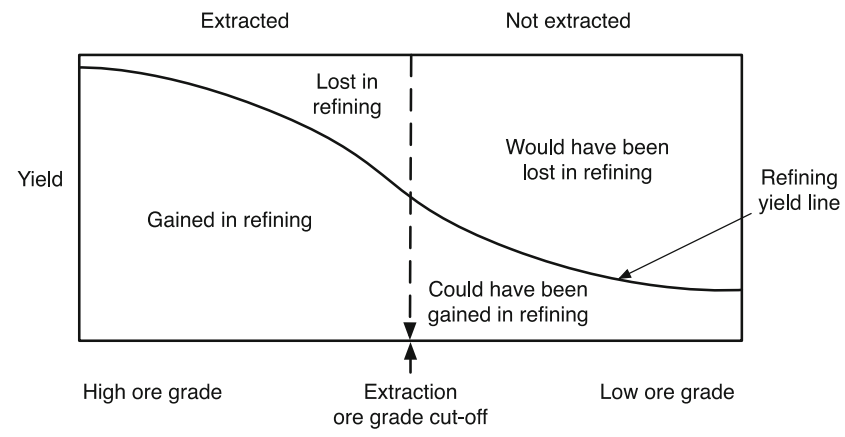

Fig. 2 Explaining the terms of ore grade cut-off and refining yield 
overall yield of the whole extraction process [26]. The extraction yield:

$$
\begin{aligned}
& Y_{E}(\text { Ore grade-extraction cut }- \text { off ore grade }) \\
& \text { Ore grade }
\end{aligned}
$$

$Y$ is the overall yield, the amount of metal extracted divided by the total metal content in the original ore. The refining yield is the yield obtained when working with the beneficiated ore. Beneficiation only works down to a specific limit. That is the point when the extraction will sometimes change method and goes to heap leaching. Then, there will be a leaching process yield and a subsequent refining yield. See 1 for an explanation of the terms for the ore grade cut-off and refining yield. The ultimately recoverable resources (URR) are estimated [25, 26, 29, 30]:

$\mathrm{URR}=M_{D} * \mathrm{Y}$

where $M_{D}$ is to total amount physically present in deposits. Figure 2 shows how prospecting efficiency decrease when there is less hidden left to find, the prospecting will be broken off.

\subsubsection{Methods for Ore Grade Classification}

For the input data to the WORLD7 model, the classification into "known" and "hidden," and within these terms, the grade classifications presented in Fig. 3 rich, high, low, ultralow, trace and gold grades will be the classification used in this study. Note that the ore grade classifications are about extraction costs as much as metal contents.

Table 1 shows the relation between ore grade, the production cost, and minimum supply price to society. The energy need is approximate, but rise exponentially with the decline in ore grade. The numbers are approximate for 2012-2015 and are based on data from gold, silver, copper, zinc, and uranium mining from many countries (data was assembled from sources like [27, 33-35] and synthesized into Table 1 by the authors).

Applying multiple repetitive extraction and separation steps increase the yield and the extraction costs. In the WORLD7 model, resources are stratified into ore quality classes, and at the starting point, nearly everything is classified as "hidden." Prospecting and finding will move it to "known" from which it will be extracted by mining. The distribution among different qualities and the production price connected to ore grade plays an important role, and with this data, extra attention was paid to checking data quality properly. The different types of stocks, where metal is held and where it can be extracted from has been defined as follows:

1. Geological sources:

a. Hidden resources: these are resources assumed or known to exists, and that will be found by prospecting and extracted at a later time in the future at cost as defined in Table 1. They are known or inferred from geological knowledge and has the extractability assessed in broad terms.

b. Known resources: these are known resources that have been demonstrated or identified; it is known where they are and are known to be extractable now or in the future.

2. Society sources

a. Stocks-in-use: is available and always make up a potential source for metal, provided the economic incentives for doing so are good enough. These include both stocks in manufacture and stocks in good use.

b. Waste or scrap is an urban ore stock that is available for recycling once the effort is made.

A large number of references related to copper deposits was consulted to make the resource estimates, and the results shown in the Tables 2, 3, 4, and 5. These references are provided as an electronic supplement as they are very many, a substantial part of them, as well as the methodology, appears in previous publications by the authors $[25,26,29,30]$, [40-43].

\subsubsection{Extraction and Production Dynamics}

The following description of the dynamics of the production and extraction is based on how it is represented in the WORLD7 model. Figure 4 shows the flow chart for nickel mining and extraction. Nickel is used in stainless steels, in plating, but also for speciality alloys, for copper and aluminium bronzes and as a chemical catalyst [44]. Nickel is mainly used in stainless steel and different types of superalloys, but there is increasing use in new battery technologies and other new speciality alloys. The ore is mined from the grade with the lowest extraction cost. The mining activity is profit-driven; the profit is affected by the mining cost and the market price. The nickel mining rate is defined by:

$$
\begin{aligned}
& r_{\text {Mining }} \\
= & k_{\text {Mining }} * m_{\text {Known }} * f(\text { technology }) * g(\text { profit }) * \mathrm{p}(\text { yield })
\end{aligned}
$$


Fig. 3 The characterization scheme employed for the assessment of ultimately extractable resources for nickel

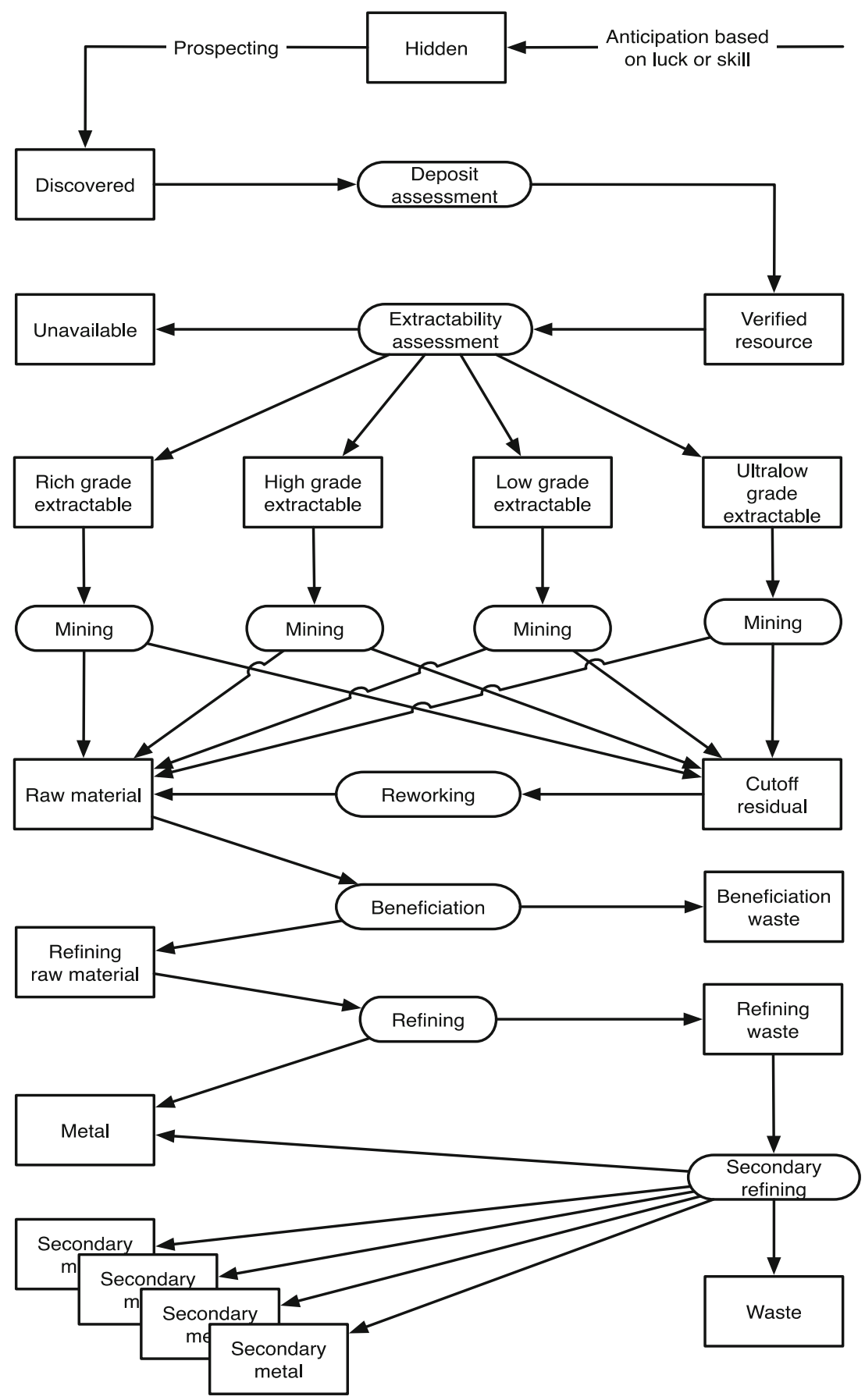

where $r_{\text {Mining }}$ is the rate of mining (million ton nickel per year), $k_{\text {Mining }}$ is the mining rate coefficient, $m$ is the mass of the ore body (million ton nickel), and $f$ (Technology) is a technology improvement function dependent on time, $g$ (profit) is feedback from profits on the mining rate. $\mathrm{p}$ (yield) is a rate adjustment factor to account for differences in extraction yield when the ore grade decreases. These functions are given exogenously to the model (Fig. 5). The mining rate coefficient is modified with ore extraction cost and ore grade. The size of the extractable ore body $\left(\mathrm{m}_{\mathrm{Known}}\right)$ is decreased by extraction $\left(\mathrm{r}_{\text {Mining }}\right)$ and increased by prospecting and discovery of more ore $\left(\mathrm{r}_{\text {Discovery }}\right)$. See equation $(6)$ :

$$
\frac{\mathrm{dm}_{\text {Known }}}{\mathrm{dt}}=-\mathrm{r}_{\text {mining }}+\mathrm{r}_{\text {discovery }}
$$

The amount of hidden resource $\left(\mathrm{m}_{\mathrm{H}}\right)$ decrease with the rate of discovery ( $\left.\mathrm{r}_{\text {Discovery }}\right)$. The rate of discovery is dependent on the amount of metal hidden $\left(m_{\text {Hidden }}\right)$ and the prospecting coefficient $\mathrm{k}_{\text {Prospecting. }}$. The prospecting coefficient depends 
Table 2 Estimated global reserves (Known) and resources (Hidden) for nickel in a million ton of nickel, listed by country, using data compiled from detailed studies. Estimates in italics are guesses made by the authors, in place of missing numbers.

"Other" comprises Africa, Middle

East, Central Asia, and Indochina.

Estimate $\mathrm{A}$ is using data compiled from detailed studies and country reports from US Bureau of Mines 1932-1995 [36] and US

Geological Survey Minerals Yearbook (1932-2017) [37], and USGS Mineral Commodities Summaries (1999-2017) [38].

Estimate B is a deposit-by-deposit tally based on the available literature, adding up the metal contents. The seafloor estimates derive from Olafsdottir et al. [39]. Amounts in a million metric ton of nickel
Table 1 Classification of ore grades used in the WORLD7 model. These are approximate extraction yields in \% for some metals

\begin{tabular}{|c|c|c|c|c|c|c|c|}
\hline \multirow[t]{2}{*}{ Region } & \multicolumn{3}{|c|}{ Estimate A } & \multicolumn{4}{|l|}{ Estimate B } \\
\hline & $\begin{array}{l}\text { Known, } \\
\text { literature } \\
\text { sources }\end{array}$ & $\begin{array}{l}\text { Hidden } \\
\text {,resources }\end{array}$ & Total & $\begin{array}{l}\text { Known, estimate } \\
\text { from National data }\end{array}$ & $\begin{array}{l}\text { Maximum } \\
\text { known from } \\
\mathrm{A} \text { and B }\end{array}$ & $\begin{array}{l}\text { Hidden } \\
\text { resource }\end{array}$ & Total \\
\hline Canada & 3 & 45 & 48 & 72.6 & 72.6 & 45 & 117.6 \\
\hline Russia & 7.9 & 20 & 27.9 & 55.4 & 55.4 & 20 & 75 \\
\hline Indonesia & 22 & 52 & 74 & 24.3 & 24.3 & 52 & 76 \\
\hline Cuba & - & - & - & 23.1 & 23.1 & 10 & 33 \\
\hline Australia & 19 & 40 & 59 & 14.4 & 19 & 40 & 59 \\
\hline Colombia & 6 & 40 & 46 & - & 6 & 40 & 46 \\
\hline Brazil & 9.1 & 30 & 39.1 & 16.1 & 16.1 & 30 & 39 \\
\hline United States & - & - & - & 15.7 & 15.7 & 10 & 26 \\
\hline New Caledonia & 12 & 12 & 24 & 2.7 & 12.0 & 12 & 24 \\
\hline South Africa & 3.7 & 10 & 13.7 & 6.5 & 6.5 & 10 & 16.5 \\
\hline Philippines & 3.1 & 12 & 15.1 & 5.8 & 5.8 & 12 & 17.8 \\
\hline Madagascar & 1.6 & 12 & 13.6 & - & 1.6 & 12 & 13.6 \\
\hline Cuba & 5.5 & 7 & 12.5 & - & 5.5 & 7 & 12.5 \\
\hline Greenland & 0.2 & 12 & 12.2 & 5 & 5 & 12 & 12 \\
\hline China & 3 & 5 & 8 & 5.5 & 5.5 & 5 & 10.5 \\
\hline Zimbabwe & - & - & - & 5.4 & 5.4 & 5 & 10.4 \\
\hline Finland & 3 & 7 & 10 & 5.0 & 5 & 7 & 12 \\
\hline Sweden & 2 & 7 & 9 & 0.2 & 2 & 7 & 9 \\
\hline Colombia & 1.1 & 4 & 5.1 & 1.4 & 1.4 & 4 & 5.4 \\
\hline Tanzania & - & - & - & 3.9 & 3.9 & 1 & 5 \\
\hline Norway & 0.2 & 2 & 2.2 & 0.2 & 0.2 & 2 & 2.2 \\
\hline Botswana & - & - & - & 0.5 & 0.5 & 1 & 1 \\
\hline Venezuela & - & - & - & 0.2 & 0.2 & 1 & 1.2 \\
\hline Other & 6.5 & 25 & $31-5$ & 0.5 & 6.5 & 25 & 31.5 \\
\hline Sum & 108.9 & 342 & 450.9 & 264.2 & 299.2 & 370 & 669.2 \\
\hline Mined to 2018 & - & - & 47 & - & - & - & 47 \\
\hline Sum all on land & - & - & 497.9 & - & - & - & 716.2 \\
\hline Seafloor & - & - & 212 & - & - & - & 212 \\
\hline $\begin{array}{r}\text { Sum, land } \\
\text { and sea }\end{array}$ & - & - & 709.9 & - & - & - & 928.2 \\
\hline
\end{tabular}

\begin{tabular}{lllll}
\hline \multirow{2}{*}{ Ore grade classification } & Ore grade, $\%$ & \multicolumn{2}{l}{ Ni refining } & \multirow{2}{*}{ Approximate extraction cost, \$/kg } \\
\cline { 3 - 4 } & & Single run & Repetitive \\
\hline Rich & $70-25$ & 95 & 95 & $1-3$ \\
High & $25-5$ & 70 & 94 & $3-6$ \\
Low & $5-1$ & 64 & 92 & $6-50$ \\
Ultralow & $1-0.05$ & 50 & 88 & $50-500$ \\
Trace & $0.05-0.01$ & 35 & 72 & $500-4000$ \\
Rare & $0.01-0.001$ & 30 & 60 & $4000-15,000$ \\
Golden & $0.001>$ & 20 & 50 & $>15,000$ \\
\hline
\end{tabular}


Table 3 Nickel. Different estimates of the total nickel extractable amounts. Million ton of nickel. (1: 130 million ton nickel is contained in ore with more than $1 \%$ content of nickel, 2: 130 million ton is nickel ore with more than $1 \%$ content of nickel. The numbers exclude seafloor nodules (MCS Minerals Commodities Summaries Programme). The studies independent of the USGS estimates are marked*

\begin{tabular}{|c|c|c|c|c|}
\hline Source of estimate & \multicolumn{4}{|c|}{ Million metric ton of extractable iron content } \\
\hline 1900; Kimbell 1963 & - & 23 & 1 & 24 \\
\hline Merril 1932 & 4.1 & 12 & 1 & 17 \\
\hline Davis 1939 & 5 & 15 & 1 & 21 \\
\hline Davis 1950 & & 50 & 2 & 52 \\
\hline Davis 1952 & & 39 & 2 & 41 \\
\hline Davis 1953 & 31 & 25 & 2 & 58 \\
\hline Bilbrey and Long 1960 & 35 & $(45)$ & 3 & 83 \\
\hline Lynde Jr. 1965 & $(40)$ & 52 & 5 & 97 \\
\hline Meadows et al., 1974 & 90 & 150 & 15 & 355 \\
\hline USGS MCS 2001 & 61 & 140 & 20 & 221 \\
\hline Mudd 2009* & 60 & 202 & 25 & 287 \\
\hline Roper $2009 *$ & 50 & 200 & 25 & 275 \\
\hline UNEP 2011 & 180 & & 28 & 208 \\
\hline USGS MCS 2012 & 75 & $230^{1}$ & 30 & 335 \\
\hline Mudd and Jowitt 2014* & 299 & & 35 & 334 \\
\hline Sverdrup et al., 2016 & 65 & 230 & 40 & 335 \\
\hline USGS MCS 2017 & 78 & $260^{2}$ & 43 & 381 \\
\hline An estimate by the authors in 2017 & 266 & 342 & 45 & 653 \\
\hline 2019: This study Table 4 & & & & 671 \\
\hline 2019: This study Table 2A & & & & 710 \\
\hline 2019: This study Table 2B & & & & 928 \\
\hline 2019: This study Table 5 & & & & 642 \\
\hline
\end{tabular}

on the amount of effort spent and the technical method used for prospecting.

Prospecting is done to find unknown but existing resources, to convert them to known and extractable reserves. When the prospecting efficiency decrease because there is less hidden left to find, the prospecting will be broken off (see Fig. 5). When the effort needed for success starts to increase because there is less hidden left to find, the prospecting will be broken off (7):

$$
\begin{aligned}
& \frac{\mathrm{dm}_{\text {Hidden }}}{\mathrm{dt}}=-\mathrm{r}_{\text {Discovery }} \\
=-\mathrm{k}_{\text {Prospecting }} * \mathrm{~m}_{\text {Hidden }} * \mathrm{f}(\text { technology }) & \mathrm{g}(\text { profit })
\end{aligned}
$$

Table 4 Nickel. The estimated ultimately recoverable amount of nickel, starting from 1900 chosen as input data to the model. All amounts are expressed in million metric ton of nickel

\begin{tabular}{lllllll}
\hline \multirow{2}{*}{ Type } & \multicolumn{7}{l}{ Ore grade classes, recoverable metal in a million ton } & \\
\cline { 2 - 6 } & Rich & High, 11\% & Low, & Ultralow, 0.5\% & Trace, 0.1\% & Sum \\
& $55 \%$ & & $2 \%$ & & \\
\hline Total deposit amount & 18 & 154 & 303 & 512 & 550 & 1,537 \\
Prospecting yield, \% & 80 & 70 & 60 & 50 & 40 & 51 \\
Known & 2 & 8 & 12 & 16 & 20 & 58 \\
Hidden 0-1 km & - & 40 & 60 & 110 & 120 & 330 \\
Hidden 1-2 km & - & 30 & 50 & 80 & 50 & 210 \\
Hidden 2-3 km & - & 20 & 40 & 35 & 20 & 115 \\
Hidden 3-4 km & - & 10 & 20 & 15 & 10 & 55 \\
Sum Hidden 0-4 km & 12 & 100 & 170 & 240 & 200 & 722 \\
Sum all & 14 & 108 & 182 & 256 & 220 & 780 \\
Extraction cut-off grade, \% & 20 & 3 & 1 & 0.3 & 0.03 & - \\
Refining yield \% & 95 & 93 & 90 & 85 & 80 & 86 \\
Extractable amount & 13 & 100 & 164 & 218 & 176 & 671 \\
URR; Cumulative sum & 13 & 113 & 277 & 495 & 671 & \\
\hline
\end{tabular}


Table 5 Sensitivity to extraction cut-off for nickel by changing the cut-off grade as compared to Table 4. The final URR is estimated considering extraction yield

Fig. 4 Nickel flow chart for nickel from deposits through society and with recycling and losses included in WORLD7. The flow of nickel is closely entangled in the system for stainless steel

\begin{tabular}{lllllllll}
\hline Extraction cut-off & $\%$ & 3.0 & 1.0 & 0.2 & 0.1 & 0.05 & 0.01 & 0.005 \\
\hline Ni total extractable & Million ton & 149 & 228 & 529 & 627 & 677 & 717 & 635 \\
Extracted to now & Million ton & 45 & 45 & 45 & 45 & 45 & 45 & 45 \\
Available for refining & Million ton & 104 & 173 & 574 & 672 & 722 & 762 & 780 \\
Bulk refining yield & $\%$ & 97 & 95 & 93 & 92 & 87 & 83 & 82 \\
URR; Ni estimation & Million ton & 100 & 164 & 534 & 618 & 628 & 632 & 642 \\
\hline
\end{tabular}

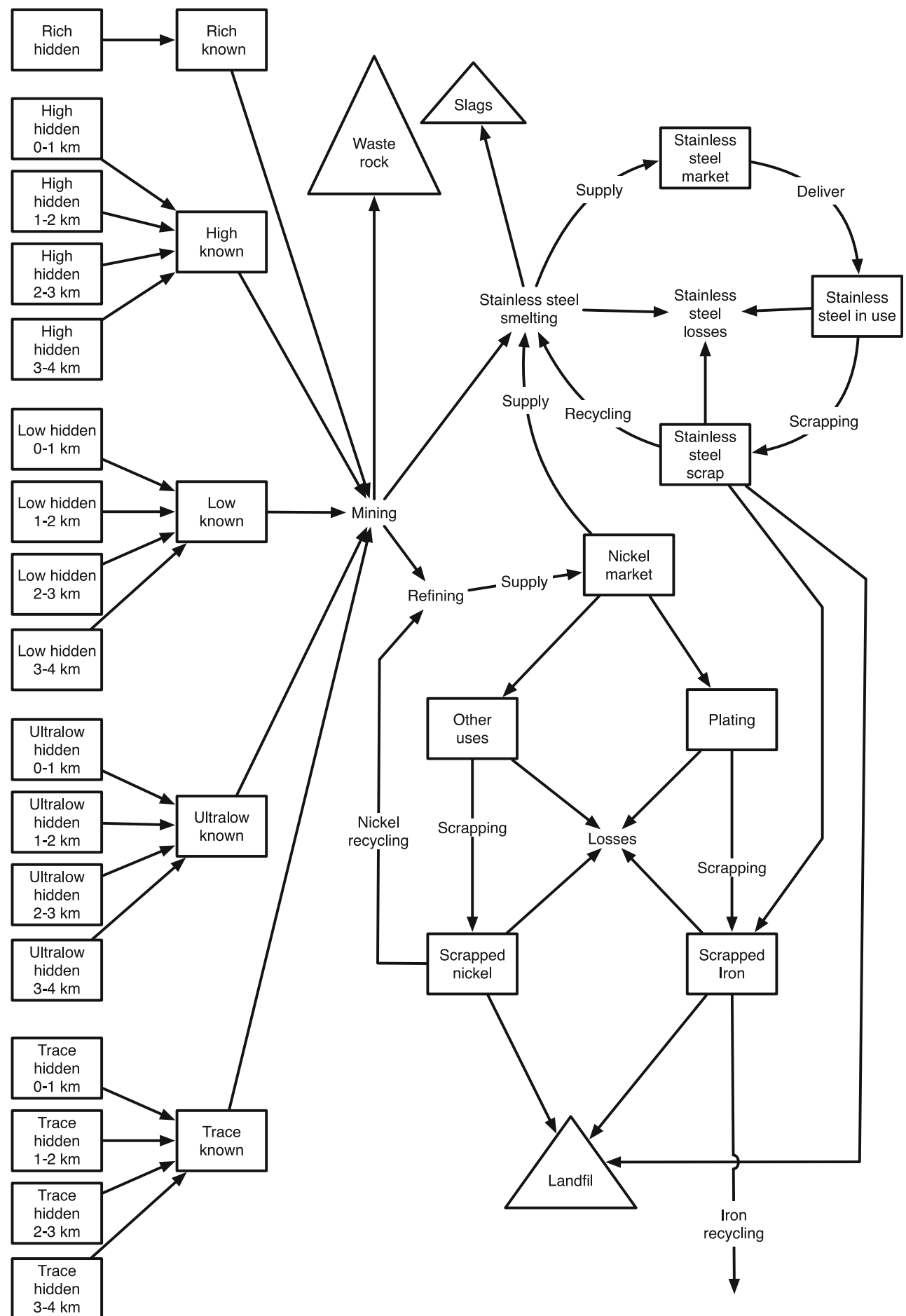


Fig. 5 Extraction, prospecting, exhaustion (B3), and profit loops for the nickel module

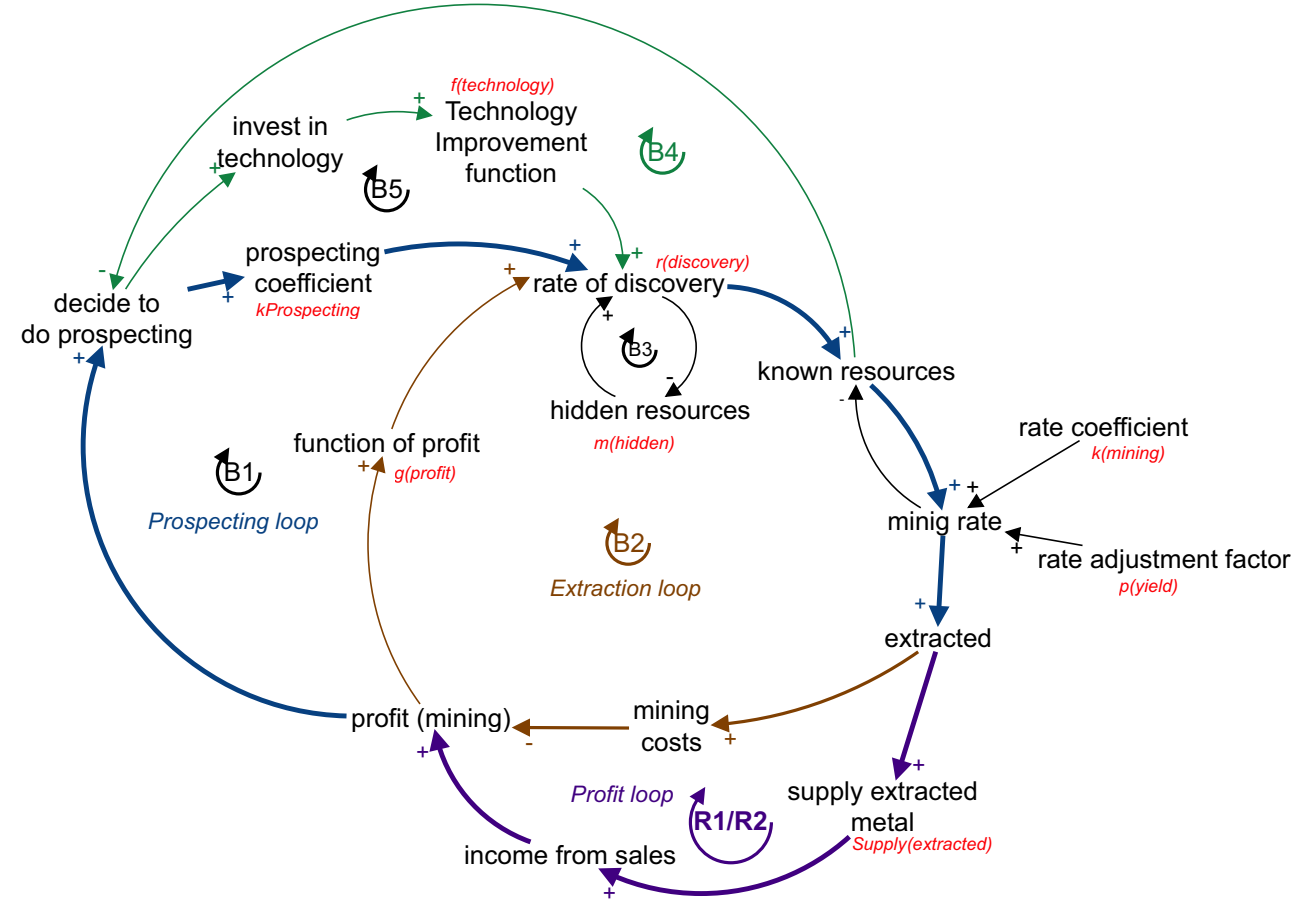

A simplified CLD representing the market model applied in the WORLD7 model is presented in Fig. 5, and Eqs. 1 and 5-7 are further explained as a causal loop diagram. It is noted that this CLD does only show part of the story. The demand is not shown, for example. To clarify the demand is present in the model (see more in Section 3.1.4). It is causally linked with the population size. The GDP has a positive link to the demand, and the demand has a positive link to what we call a modified demand. The modified demand is the demand that has been adjusted for price, i.e., if the price increases, one is likely to buy less than the mind desires. The modified demand is the amount that is taken from the market (through delivery). The amount on the market affects the price based on market dynamics, more supply, less price and vice versa.

The mining rate is driven by profits and the availability of extractable resources in the model. Scrap is both lost physically by dropping it where it cannot be found:

$$
\mathrm{r}_{\text {Scrap loss }}=-\mathrm{k}_{\text {Scrap loss }} * \mathrm{~m}_{\text {Scrap }}
$$

For nickel, the smelting equation includes secondary sources from copper mining and platinum group metal mining:

$$
\begin{aligned}
\mathrm{r}_{\text {Nickel }}= & \mathrm{k}_{\mathrm{Ni} \text { smelting yield }} * \mathrm{r}_{\text {Nickel mining }}+\mathrm{r}_{\mathrm{Ni} \text { from PGM }} \\
& +\mathrm{r}_{\mathrm{Ni} \text { from } \mathrm{Cu}}
\end{aligned}
$$

Table 1 shows the relationship between ore grade, the approximate production cost, approximate extraction yield and minimum supply price to society. The following equation defined profit in the extraction activity:

Profit $=$ Income from sales-mining costs

The mining activity is promoted by a function depending on the profit being positive. Where the total costs are defined as costs of:

Total costs $=$ Mining costs + refining costs

$$
+ \text { prospecting costs }+ \text { investment costs }
$$

In this equation, mining costs, refining costs, and prospecting costs include variable operations costs and also comes capital costs for infrastructures and equipment. In the model, purchases from the market are driven by demand. Delivery from the market goes into the society where it stays until scrapped, removed by wear or losses. A part of the scrapped metal is recycled and returned to the refinery. Metal production is demanding energy. The energy use for nickel is calculated for the extraction of the ore, the enrichment of the ore from raw rock to ore concentrate and smelting or refining to the final metal or alloying component is estimated in the model. When ore grade decline, the energy use increases and this is considered in the WORLD7 model. For nickel, the ore grade is declining, and the energy used for extraction increase steadily [45]. When the energy use for all the metals included approach about $65 \%$ of the total energy available, then the metal production is reduced. 


\subsubsection{The Market Model}

The market model applied in the WORLD7 model can reconstruct price histories for various commodities and therefore includes predictive price capabilities [30, 44, 46-49]. In the WORLD7 model, the feedbacks cause higher prices to decrease demand but increase profits and push for more extraction. Prospecting is done to keep the amount of known ore at a level sufficient for mining. The prospecting find rate depends on the intensity of prospecting and the amount hidden ore available to find. When the intensity increases without any response in find rate, then the prospecting is stopped. That signals when the resource has been exhausted. Locally, resource extraction is a well-known phenomenon, and global exhaustion is an issue of adding up all regional resources to the global level. Costs and profits are made into disposable income, in turn, driving consumption and in the next step demand. The mining cost is driven by two factors in the model, the energy price and the ore grade. The ore grade determines how much material must be moved and treated to make ore concentrate for extracting the metals. There are several reinforcing loops that drive the system towards more extraction. Mining creates profits when selling the product and profits drives extraction. Recycling creates recycling profits, which will drive more recycling. Exploration finds more resources, allowing for more mining.

Demand in the model is driven by population, GDP per person per year and a use per person with the same curve shape over time as copper use per person, but is adjusted up or down with the price. It is assumed that the present type of society with international trade and general rule of law and order as it is today will persist over the time considered (18502250). The price is set relative to how much metal there is available in the market [41], see also London metal Exchange documentation $[50,51]$. The price is used to modify the demand. Industrial activities contribute through wages and profits to the overall disposable income in society, which in turn contributes to consumption and demand, a reinforcing loop. The price affects supply indirectly by affecting mining profits, which in turn affects the mining rate, which again affects supply to the market. The amount in the market sets the price, which has feedback on supply and higher prices presses down demand. This pathway has some delays, causing the price at times to fluctuate for metals with small market stocks that can be mobilized for trade.

This profit is driven by metal price, and the amount of metal extracted (income from sales) supplied to the market but decreased by the cost of operation (see Fig. 5). The market amount to market price relationship equation could be determined for nickel (Fig. 6a). When no data was available or very little, for creating a price curve for a commodity, then the data is fitted to a curve to Eq. 12. Fig. 6a relates the amount nickel immediately tradable in the market to the market price in $\$$ per ton in the same moment [41].

For nickel (the top 10 producing companies have a $66 \%$ market share), there are several actors, allowing for an effective competing market. The curve maintains the same shape throughout the period but shifts somewhat over time. The curves allow us to set $k=48,777, n=-0.3$, with $r^{2}=0.67$. The data is fitted to a curve, according to Eq. 12 [40]:

Price $=\mathrm{k}^{*}(\text { Market stock })^{\mathrm{n}}$

\subsection{Data: Nickel Reserves and Resources}

Several published estimates for total nickel reserves and resources were used in this study. Mudd et al. [52] report nickel resources with 118 million ton of nickel in sulfides and 181 million ton of nickel in laterites, summing up to 299 million ton of nickel content. New data has been published since 2010, and this has been included in the analysis. The assessments of copper resources estimated by Olafsdottir and Sverdrup [44] influenced the estimates presented in this paper, as nickel and copper are often found in the same type of deposits and follow each other. The estimates for Canada and Russia are probably still underestimated, considering the geology and huge land surface area of those two countries. For nickel resources, a database for all copper, nickel, and molybdenum deposits were made, and the extractable ore at different extraction cut-offs estimated. Nickel occurs both in its deposits and in polymetallic deposits with chromium, cobalt, copper, and platinum group metals. Cobalt, platinum group metals, and copper are regularly recovered with nickel. Nickel and copper are also following some platinum group. Many copper deposits have significant amounts of nickel, and nickel is a by-product at such mines.

Table 2 shows estimated global reserves and resources for nickel in a million ton of metal content, listed by country, using data compiled from detailed studies and country reports as well as the US Bureau of Mines [36], US Geological Survey Minerals Yearbook (1932-2017) [37], and the USGS Mineral Commodities Summaries (1999-2017) [38], called Estimate A in Table 2. A deposit-by-deposit tally, adding up the contents [52] was made, called Estimate B in Table 2. Not all deposits in each country could be found with ore body size and ore grade, thus in estimate B, information from Estimate A was used. The maximum of the two estimates was used. Of the global nickel deposits, it is estimated that about $60 \%$ is situated in laterites and about $40 \%$ in sulphide deposits. The result is that Estimate A indicates that the URR for nickel is about 500 million ton of nickel on land, and Estimate B suggests that URR is 716 million ton of nickel on land. 

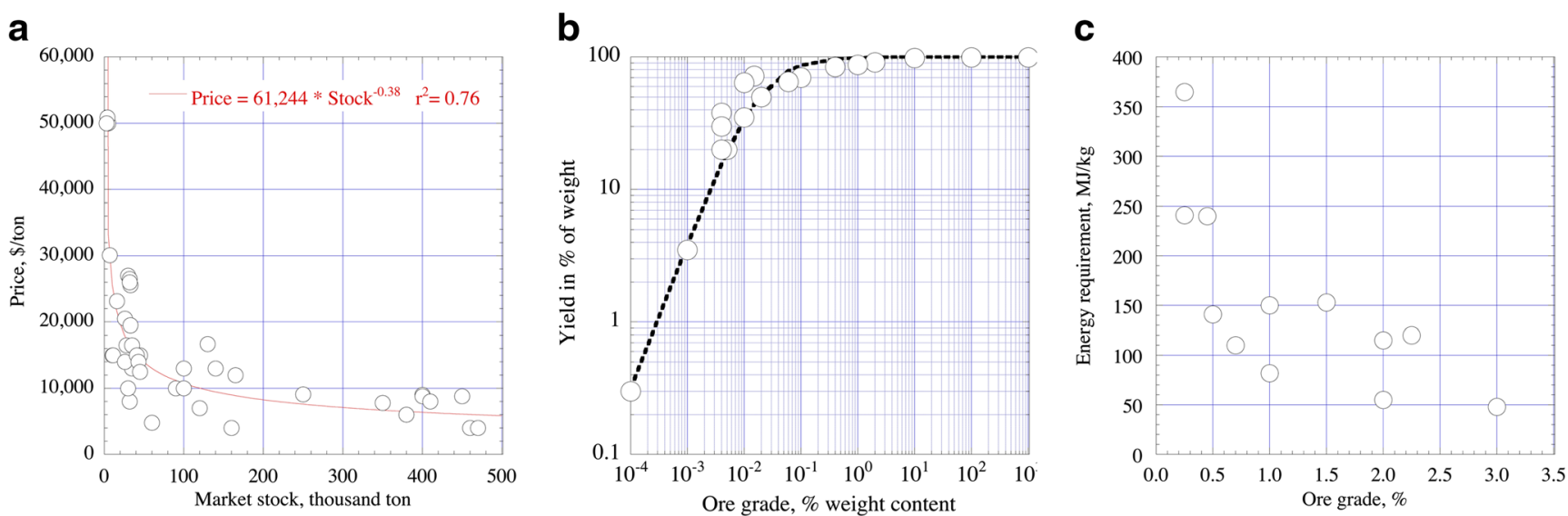

Fig. 6 a The diagram shows the market curves for nickel, b refining yield \% vs weight content per refining step, and (c) energy requirement and ore grade for extraction of bulk ore and metal

Ocean seafloor mining does not yet occur, and no operational method for putting it into full operation do not exist. The potential resource is estimated to about 212 million ton of nickel if anyone finds how to do it operationally and environmentally safe. The ocean floor URR for copper is orders of magnitude lower than the detected amounts present in massive underwater sulphides, cobalt crusts manganese nodules and other deep-sea deposits. For ocean floor mining, it must be said that the technical and environmental challenges are enormous and mostly unsolved [39]. In the database, all known extractable deposits and all anticipated resources and estimates of still undiscovered resources are listed. A total of 237 different significant deposits or groups of deposits were assessed for their nickel content. Table 3 shows estimates of the total nickel extractable amounts, estimated at different points in time. Summing it up in a deposit by deposit assessment, the total estimate sums up in the range of 700-900 million ton of nickel. The nickel resources were estimated to an assumed maximum mining depth of $4 \mathrm{~km}$, the same as is considered to be the maximum for platinum mining in South Africa. At greater depth, the heat becomes intolerable for humans, and the mountain pressure is so immense that it starts to get very problematic to keep the tunnels stable. That makes it challenging to do the work with robots as substitutes for humans. Cooling machinery has capacity problems below $4 \mathrm{~km}$, and the rock stability problem is an issue. Mountain pressure would make any mining below $5 \mathrm{~km}$ depth unrealistic.

It is noted that the majority of $\mathrm{Ni}$ mineralization occurrences across the world differ from $\mathrm{Cu}$ deposits. How this is reflected in the WORLD7 model can be seen in

Fig. 7.

Fig. 8 shows the development of estimated ultimately recoverable nickel resources with time from data found in the literature see Table 3 . The data used for the diagrams have been listed in the tables in this paper. When an s-shaped curve can be seen, it indicates that most of the "hidden recourses" has been found, resulting in the final estimate. The plot for nickel shows that the resource estimates are increasing with time recently. The assessments suggest that the nickel resource is in the size of 700 million ton. This suggests that there may be more substantially nickel to be found, but it cannot be assumed that it can be extracted just because it is found. A general result is that the extractable resources of nickel appear to be larger than earlier studies would indicate. It is almost sure that more deposits with significant amounts of nickel will be found; however, the critical issue will be how much of that will be extractable at a price society can pay.

Table 4 shows the ultimately recoverable amount nickel, from 1900, with the amounts grouped into rich, high, low, ultralow and trace ore grade. Note that the estimated deposit amount is 1537 million ton, far more than earlier available estimates. Note that this is not all available for extraction, but subject to reductions from physical access to the deposit, the ore preparation cut-off grades and the refining yields. All of this sums up to an estimate where about 670 million ton of nickel that will be available for extraction provided the energy and funding are available to do the extraction, and that there is a corresponding demand to take it off at the actual price. For each of these ore quality groups, the nickel resources are each divided into $0-1 \mathrm{~km}, 1-2 \mathrm{~km}, 2-3 \mathrm{~km}$, and 3-4 km mining depth. This was used as the starting point for the nickel submodel.

Ore grades follow the scheme laid out in Tables 2 and 3. Cut-off used for nickel varies from $1 \%$ down in low grade to as low as $0.1 \%$ in ultralow grade and trace grade ores. The nickel content in platinum group metals (PGM) ores are on the average 500 times the PGM content. That implies that when there is $3 \mathrm{~g}$ per ton PGM, then there is $1.5 \mathrm{~kg}$ 

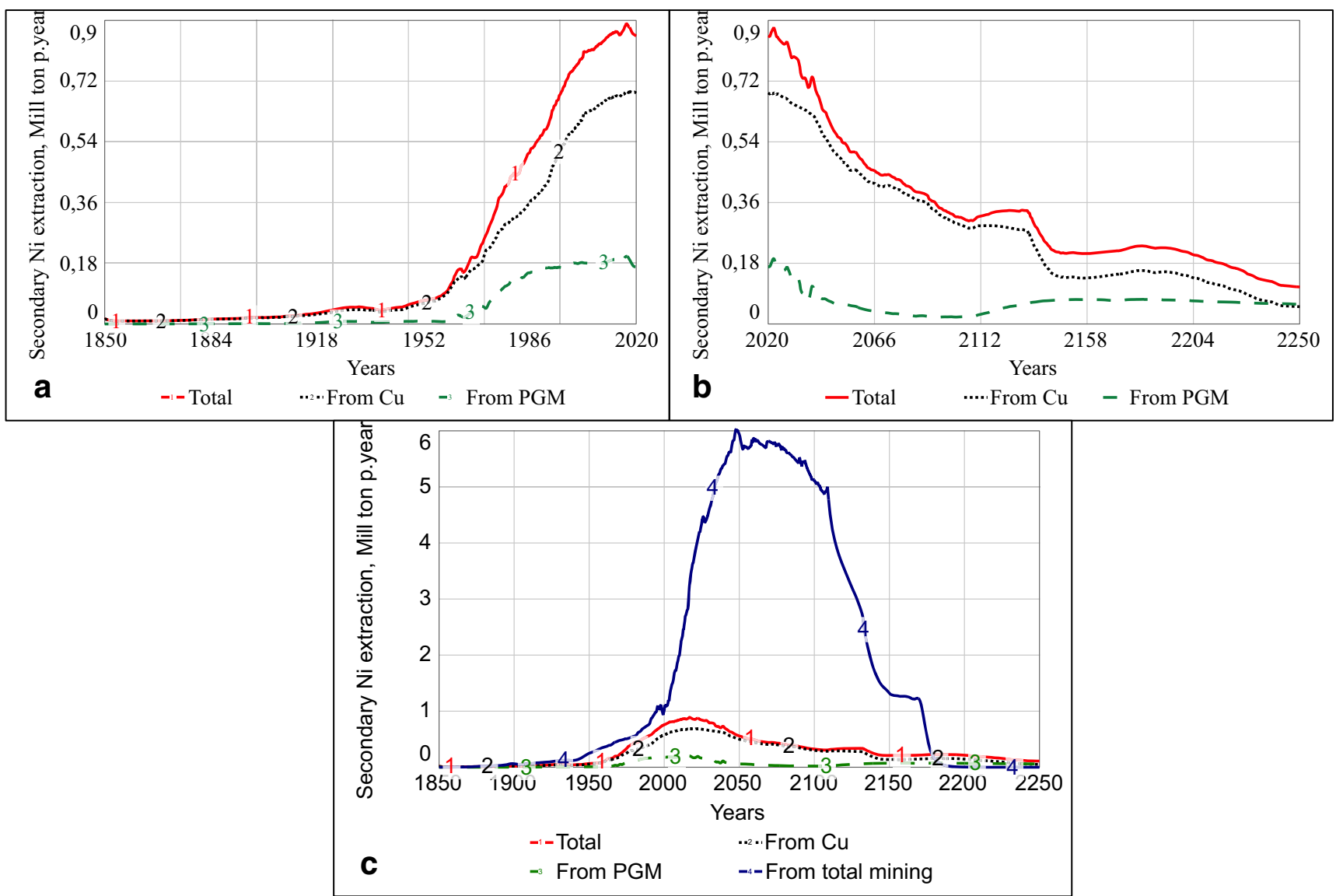

Fig. $7 \mathrm{Ni}$ from $\mathrm{Cu}$ and platinum group minerals for a the past from 1850-2020, $\mathbf{b}$ the future prediction from 2020-2250, and $\mathbf{c}$ as compared to the total $\mathrm{Ni}$ mining for past and future together

nickel per ton in the ore $(0.15 \% \mathrm{Ni})$. It is assumed that the copper ores that have nickel have on the average 0.035 times the copper content. Table 5 shows the effect of using different extraction cut-off limits for the extractable amount. Typical operational cut-off grades in 2015 were in the range of $0.2-0.1 \%[46,47,51,52]$.

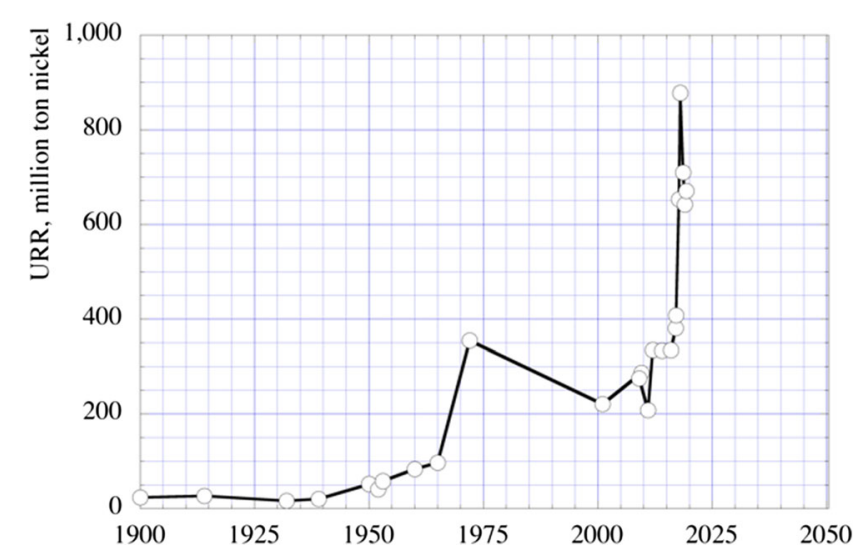

Fig. 8 The development of estimated ultimately recoverable nickel resources with time from data found in the literature

\subsection{Model Validation}

The performance of the WORLD7 model for nickel was tested on field data to assess its reliability. The model test on historical data lends credibility to predictions made for the future and supports the use of the model for strategic policy development. The model was tested on data from the past (1850 2020).

Fig. 9 shows validation tests in which observed data is compared to simulation outputs. Fig. 9a and b shows the mined and the cumulative amount mined as compared to the observed for nickel from 1850 to 2020, and Fig. 9c the price simulation for nickel for 1850-2020. The correlation coefficient for extraction rate is $\mathrm{r} 2=0.88$, price is $\mathrm{r} 2=0.52$, and for the ore grade $\mathrm{r} 2=0.74$. The model outputs show that it is possible to simulate demand, modified demand, supply to society, production, recycling, and ore grades. The peak in modern times is reproduced, but with a slight miss in timing. This inconsistency may be caused by uncertainty in setting delay times precisely in the model. Fig. $9 \mathrm{~d}$ shows the ore grade compared to data from 1900 to 2020 . The data available is not reliable enough before 1900, and therefore the comparison 

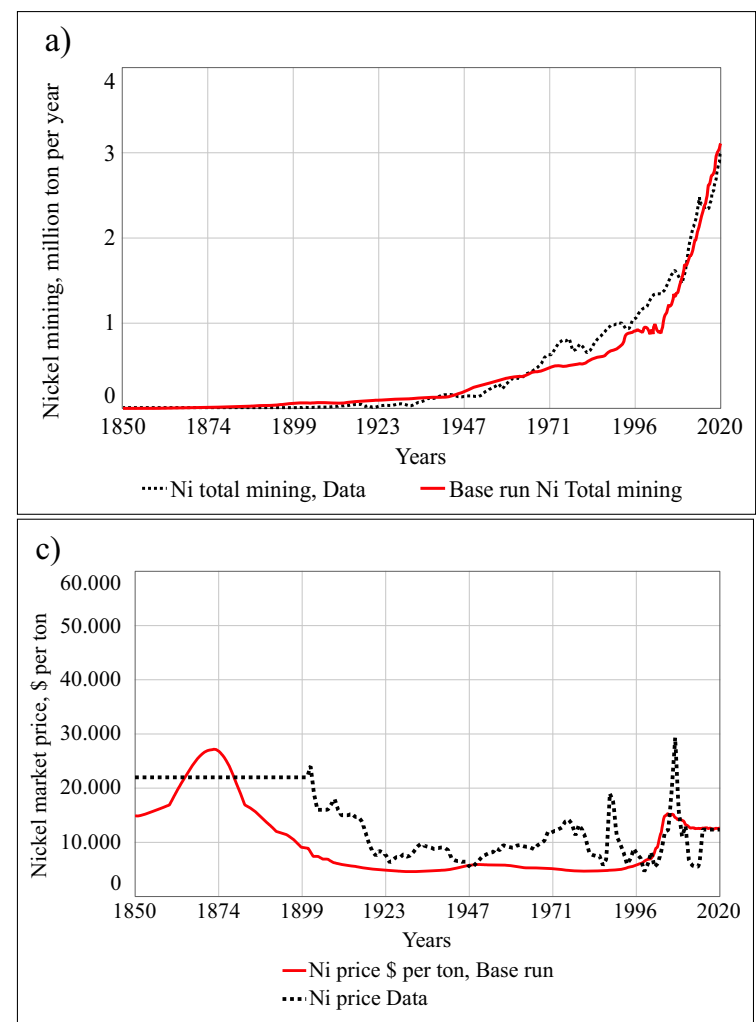

Fig. 9 Validation graphs, simulation output compared to data from 1850 2020. a The amount mined, $\mathbf{b}$ the cumulative amount predictions, and $\mathbf{c}$ the price simulation for nickel and $\mathbf{d}$ ore grade. The ore grade is only

starts there. The graph shows that the fit between the simulated ore grade and the observed data is good.

\section{Results}

The results are based on simulation outputs predictions, from 2020 to 2200 , based on the Base run and sensitivity runs varying initial values for some key variables are also considered (unless another period is considered more relevant). Note that the Base run is the simulation output based on all the assumptions and estimations believed to reflect reality best. The base run was also used for the validation test (Section 3.4.).

\subsection{Results from the Base Run}

Fig. 10a and $\mathrm{b}$ shows the mining predictions and the cumulative mining based on the Base run from 2020 to 2200. Fig. 10d shows the $\mathrm{Ni}$ ore grade predictions. It is noted that the graph is presented in a longer time scale compared to the other graphs to show better the decline; the timeline is from 1900 to 2170 . Declining ore grades for these metals will have severe implications for energy use and metal production costs. Fig. 10c shows Ni price predictions. Decreasing ore grade causes

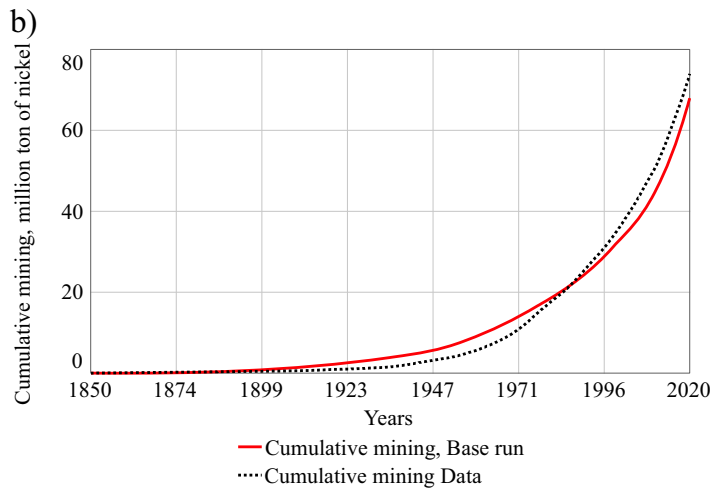

d)

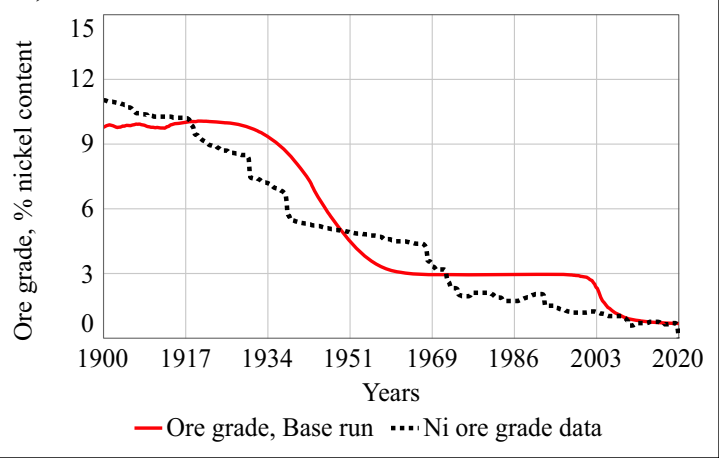

compared to data from 1900 as the available data is not reliable enough for comparison before that

increased extraction costs, requiring a higher market price. Higher market price may introduce demand decreases. This rising price will mostly affect the price of stainless steel, and nickel scarcity implies that stainless steel may become scarce as well. Indeed, this is what was observed in the connected stainless steel simulation [53]. The WORLD7 model well reproduces the trends, but the model does not capture the shortterm variations in price.

Fig. 11a shows the results for nickel extraction from different ore grades. The best ore grades are extracted first, resulting in a declining ore grade. The extraction costs for metals go up exponentially with declining ore grade. Declining ore grades are one of the most certain diagnostic indicators of oncoming resource scarcity. For nickel, the ore quality decline has been systematic since the 1930s. The implications of declining ore grades for nickel have considerable consequences.

Fig. $11 \mathrm{~b}$ shows the demand, the actual supply, the extraction, and the recycling for nickel from 2020 to 2200. Nickel extraction was distributed among primary nickel extraction and several different secondary nickel contributions from copper, and platinum group mining. The dominating use of nickel is for stainless steel. It is the metal setting the limit for how much stainless steel can be produced. In the model, the demand for nickel is driven by stainless steel production, but 

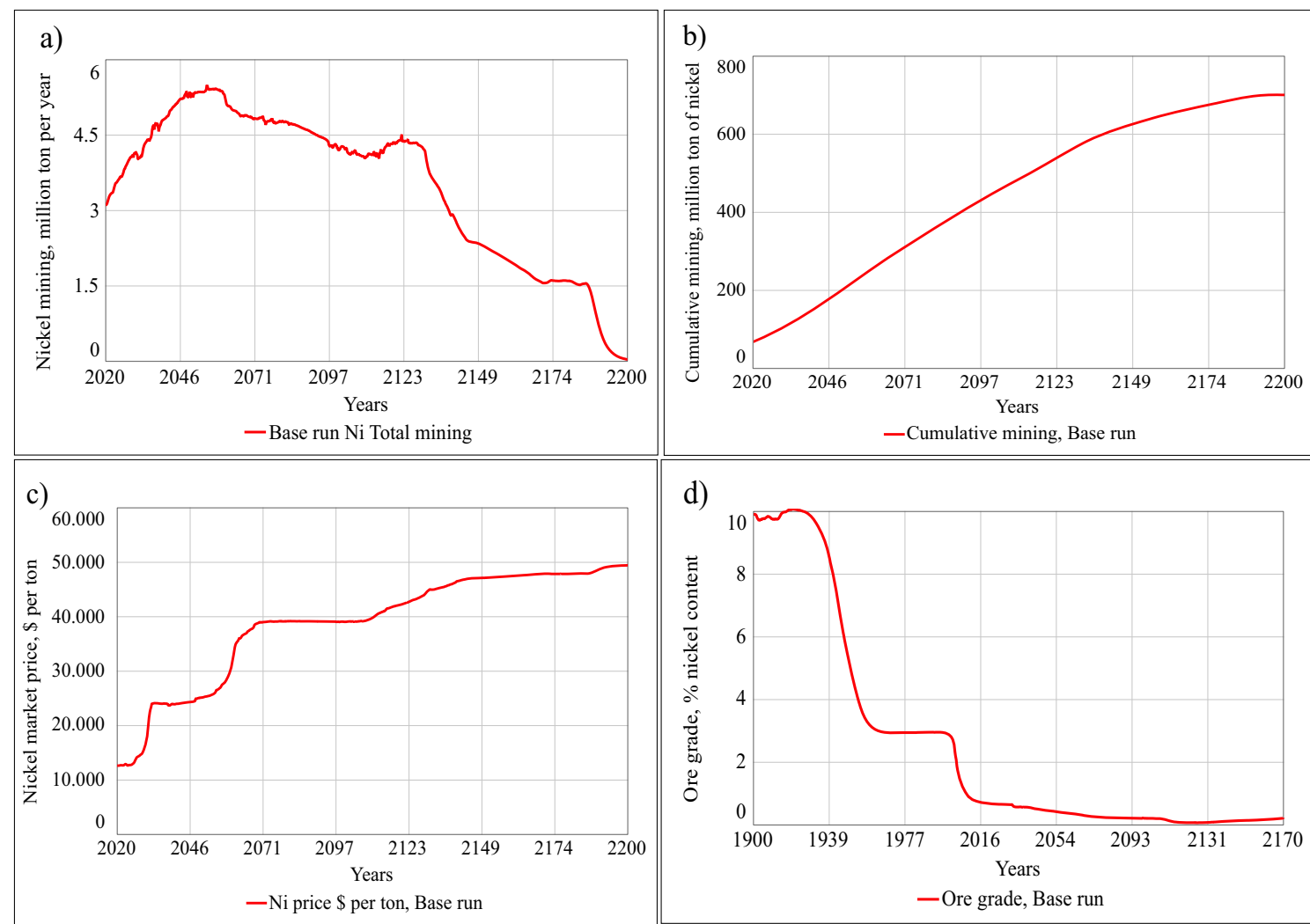

Fig. 10 Predictions from 2020 to 2200 based on the base run for a the amount mined, $\mathbf{b}$ the cumulative amount predictions, and $\mathbf{c}$ the price simulation for nickel and $\mathbf{d}$ ore grade from 1900 to 2170 (validation figures including history data compared to simulation, for these outputs are presented in Fig. 9)

also by its use in superalloys and plating. In many sulphide ore deposits, nickel and copper come together. The price is driven by a high demand when the extraction becomes limited and the steadily increasing extraction cost, caused by declining ore grade. The systemic supply and systemic demand separate, showing demand-supply separation, implying physical nickel shortage suggesting that nickel will be subject to soft scarcity. This scarcity drives the simulated price up as is seen in Fig. 10c. The rising price going on after 2020 is the manifestation of scarcity and which becomes permanent after 2030. The total recycling degree of nickel is shown in Fig. 11c. The systemic term implies both direct recycling of metal where nickel is the dominant element and refined to pure nickel. It includes when nickel is recycled as stainless steel. It can be reused or re-alloyed to new stainless steel. Recycling is price dependent. Most of the nickel used for plating is lost during use or when the plated object is scrapped. When recycled with scrap iron, it disappears into bulk iron, from which it cannot be retrieved. After 2130, only secondary nickel is available for extraction. Fig. 11d shows the known reserves, and Fig. 11e shows the hidden resources of nickel in a million ton of $\mathrm{Ni}$ content. After 2150, nickel will be exhausted from the deposits. Fig. 11f shows the stock in use per person (see discussion in Section 5.2).

\subsection{Sensitivity Analysis}

The sensitivity runs were made using the built-in feature for this in the STELLA software. Table 6 and Fig. 12 show an overview of the changes made for two of the sensitivity runs tested. The variation presented focus on different levels of the initial amount of the hidden resource estimates that affect the amount of ultimately recoverable resources of nickel (from the start of the simulation in 1850) and also different levels of $\mathrm{Ni}$ demand. The sensitivity runs in Fig. 13 are focused on nickel resource size (see input variations in Fig. 12a and Table 6) and the ones in Fig. 14 focus on Ni demand variations. The first run in Fig. 13 is based on 200 million ton less hidden resources in 1850 than the base run (run $\mathrm{nr} 3$ ), the second run is based on 100 million ton less hidden resource in 1850, run 4 shows 100 million tons more than the base run in 1850 and run 5 shows 200 million ton more. The simulation outputs indicate that even though the outputs naturally reflect the parameter settings for the ultimately recoverable resources (URR), the model still manages to simulate the past (18502017) rather well. The future predictions vary a bit based on the initial estimates, although when looking to the year, 2250 most outputs describe the same reality. 

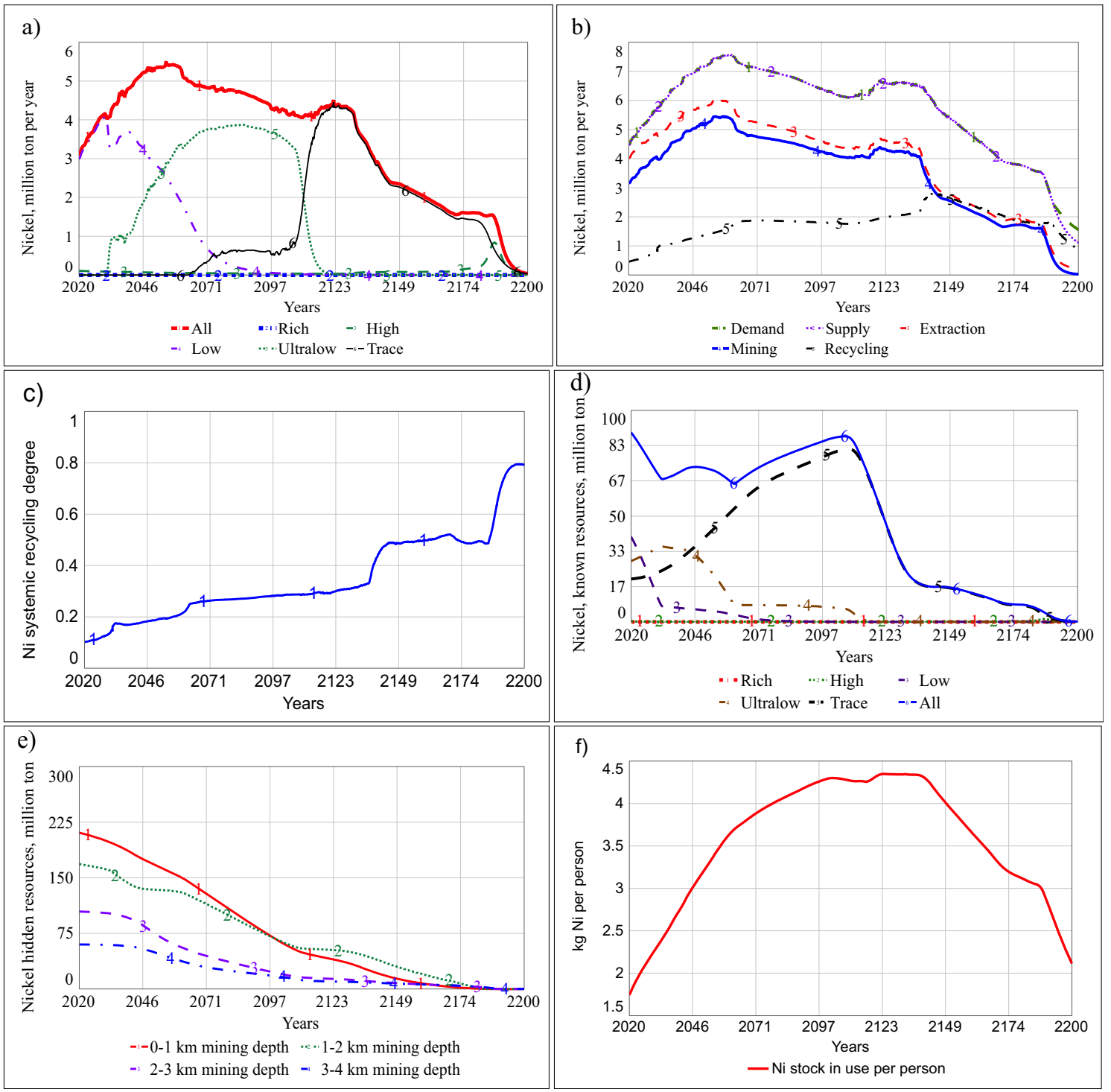

Fig. 11 Predictions from 2020 to 2200 based on the base run for a extraction of nickel from different ore grades; b the systemic supply, demand, extraction and recycling; $\mathbf{c}$ the degree of recycling of nickel as

a fraction of supply; $\mathbf{d}$ the known reserves for nickel, divided into the ore grades rich, high, low, and ultralow; e hidden resources of nickel in a million ton of $\mathrm{Ni}$ content. $\mathbf{f} \mathrm{Ni}$ stock in use per person

Looking at Fig. 14, that is based on variations in Ni demand, first, run with only $50 \%$ of the demand in the base run, the second run reflecting $75 \%$ of the Ni demand compared to the base run, the fourth run reflects $125 \%$ of the Ni demand and the fifth and last run reflects $150 \%$ of the $\mathrm{Ni}$ demand in the base run. Increased recycling has the same effect as an increased resource or a smaller demand on the timing of the maximum production. The simulation outputs indicate that even though the outputs naturally reflect the parameter settings for the Ni demand, the model still manages to simulate the past (1850-2017) rather well. The future predictions vary a bit based on the initial estimates, although when looking to the year 2250 , most outputs describe the same reality. The result of this analysis, i.e., looking into different parameter settings for the demand and the ultimately recoverable resources (URR) estimated, strengthens the assessment made
Table 6 Overview of the variations used in the sensitivity runs, see Fig. 12

\begin{tabular}{lll}
\hline Runs & Variables & Variations \\
\hline S1 & Nickel hidden recourses in1850, million ton & $376-476-576$ (Base Run) $-675-776$ \\
S2 & Nickel demand & $50-75-100 \%$ (Base Run)-125-150\% \\
\hline
\end{tabular}




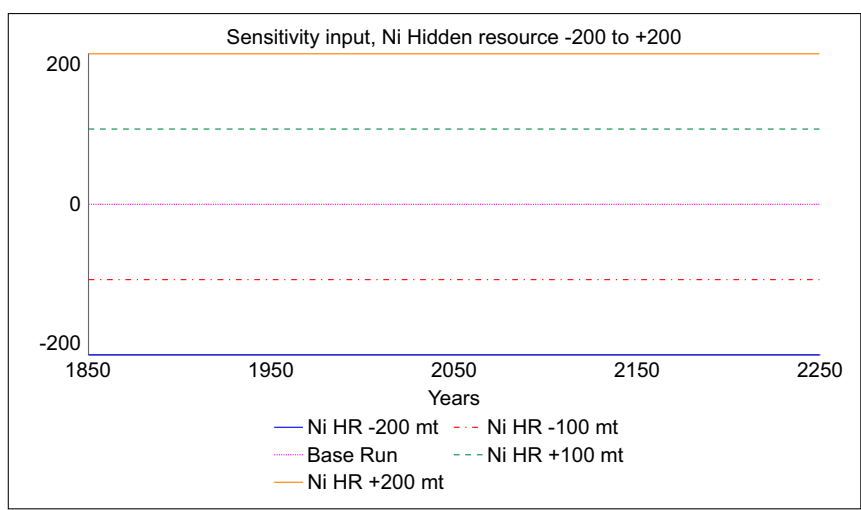

Fig. 12 a S1: input variations to the hidden nickel resource for a sensitivity analysis. 1. Run is 200 million ton less hidden resources than the base run (run nr 3), the second run was 100 million ton less hidden resource in 1850 , run 4 shows 100 million tons more than the base run

from the model as it is not super sensitive to some fluctuations in these parameter estimations.

The size of the ultimately recoverable resources (URR) and the demand play a central role in the assessments based on simulation outputs. Demand is sensitive to global population size, and the population is upward limited by resource availability inside the WORLD7 model. Therefore, it is quite right that the success of the WORLD7 model depends on the right parameterization. We have shown with this sensitivity analysis that up to $50 \%$ increase or decrease in demand, or up to $35 \%$ increase or decrease in the initial estimates for the hidden Ni recourses, still allows the model to capture the past and for the most part make similar future predictions strengthening the dynamic structure estimates underlying the WORLD7 model.

\section{Discussion}

\subsection{Uncertainty and Robustness}

The main limitation of any process-oriented model is that whatever is not represented in the model, cannot affect the outputs. When the model satisfactorily recreates what is observed, that can be interpreted to imply that the necessary and essential parts of the system have been captured. In modelling a system, a choice must be made: what to include in the model and represent well and what to put in the assumptions. A simple model is easy to operate, but it has limited content and flexible dynamics, but it can only answer simple questions. The complexity of the system is inherent to the system and cannot be changed, and ignoring them does not make them go away. A complex model considers more aspects and will have more dynamics and feedbacks.

It can be used to answer more complex questions, and the assumptions will be more straightforward, as complexity is moved from the assumptions and represented in the model.

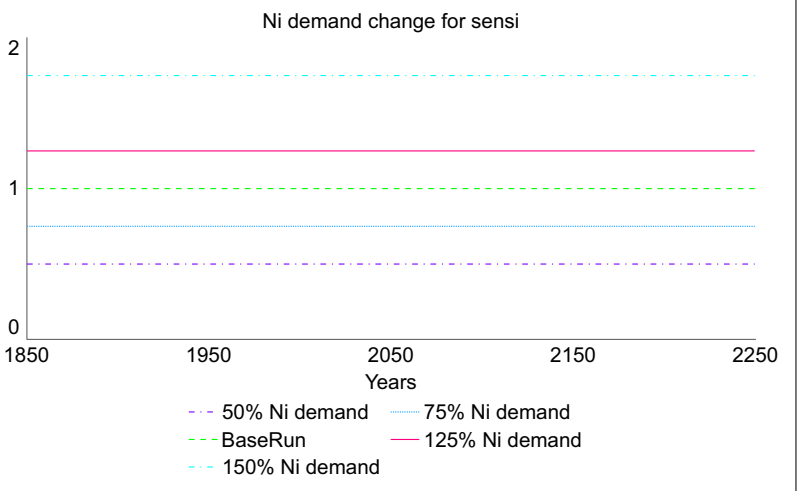

and run 5 shows 200 million ton more. b S2: input variations to the $\mathrm{Ni}$ demand, first run is $50 \%$ of the demand in the base run, and then incremental step change of $25 \%$, last run with $150 \%$ demand compared to the base run

The philosophy of the WORLD7 model is a balance between these aspects outlined above. Each module should be reasonably well representing the system, but without going to excessive details. The WORLD7 model consists of very many simple sub-modules which interact through many coupled feedbacks, generating a flexible and dynamic system.

\subsection{Peak Behavior}

Why do we see peak behaviour? What drives it? The mining curve shows peak behavior (Fig. 11a). Further and more important, the stocks-in-use per person shows a peak behavior (Fig. 11f). The main reason for the peak behavior comes from the peaking population curve, combined with increasing demand per person and declining resource. The pattern is typical of the "overshoot and collapse" systemic archetype. Population correlates with the number of consumers and therefore also with consumption. A declining fossil fuel production leads to a lower purchasing power and stagnation of economic growth (Sverdrup 2019). The implication is that the price of nickel will go up, and the nickel supply in ton metal will decline after 2070-2090.

\subsection{The Risk for Scarcity}

For assessment of soft and hard physical scarcity, two metrics for indicating whether there is a scarcity or not is used in this study $[7,54]$ those are supply per person per year and stocks-in-use per person. For any resource, the supply per person every year is used to increase the stock-in-use or lost in some way, either in transactions of production and use or by wear and tear. When the stock-in-use increases, assuming the use efficiency to stay the same, growth in service provision from that resource will also happen. The stock-inuse per person is usually the diagnostic indicator for the utility of the use of the resource. 

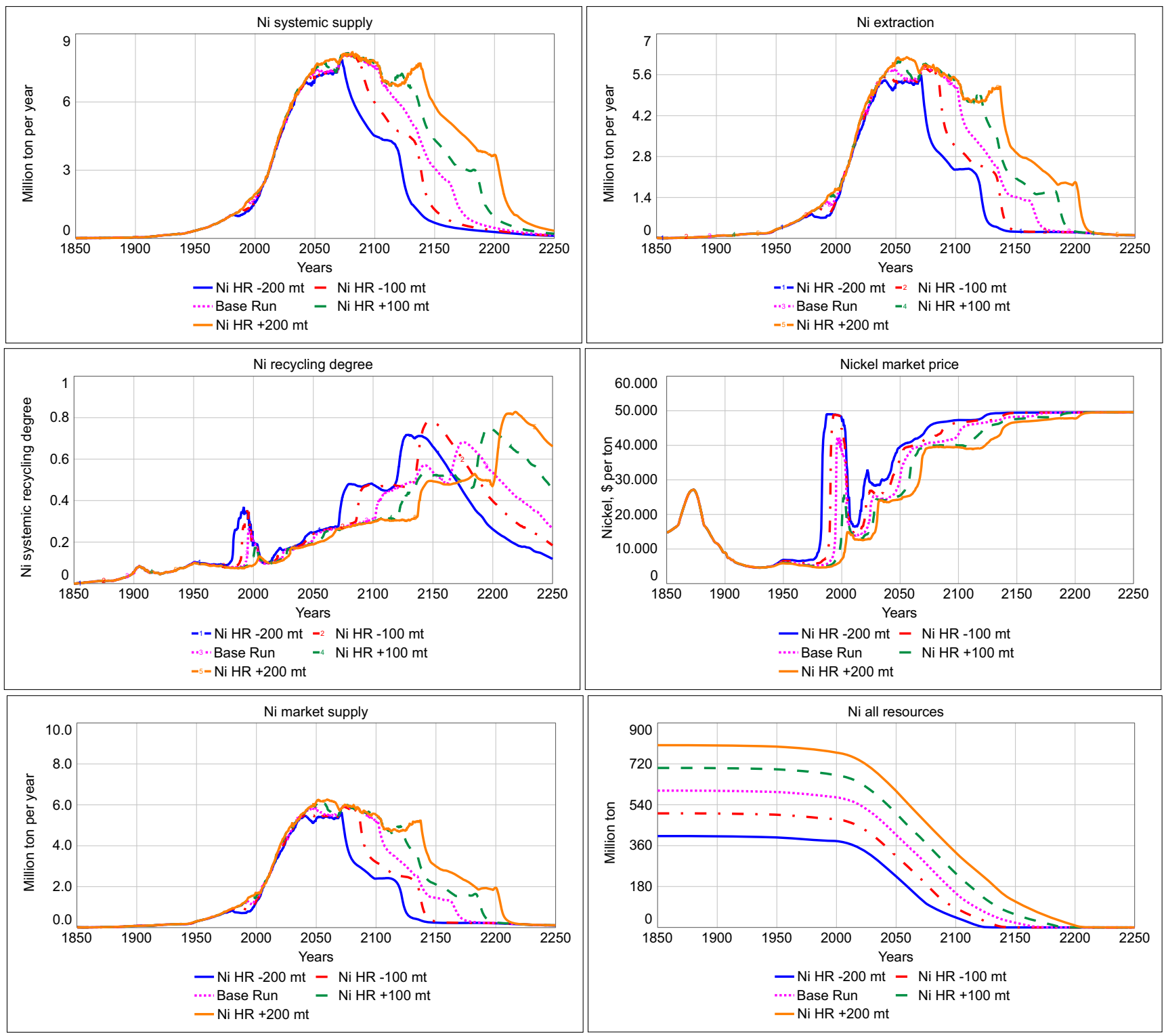

Fig. 13 S1: A sensitivity run varying nickel hidden resource amount initial value (from 1850). The first run is based on 200 million ton less hidden resources than the base run (run nr 3 ), the second run is based on

Fig. 15 shows the sensitivity runs for Ni supply per person in kilograms and stock in use per person for both S1 and S1 inputs. The curves suggest the onset of severe nickel scarcity after 2150. It shows the amount available every year to replace losses eventually create growth. Declining supply that is not matched by an efficiency improvement will lead to contraction of the service provision system. Take care to note that there is no more growth in supply after 2050 (see Fig. 13). After 2100 , there is a contraction of the stock-in-use per capita. After 2200, nickel will for practical purposes run out (Fig. 15). Reduced demand, combined with more resources, may stretch the supply peak from 2070 to 2140 , an improvement of 70 years. Note the difference in scale, stocks-in-use represents about 6 years of supply. A decline in the stock-in-

100 million ton less hidden resource than the base run, run 4 shows 100 million metric tons more than the base run and run 5 shows 200 million metric ton more

use per person is the same as a decline in the provision of service. The declining nickel ore grade is one of the most certain diagnostic indicators for oncoming resource scarcity (Fig. 10d). The implications are apparent, with lower ore grade, the more work and the more cost must be spent to get the metal out. Improvements in technology have been used to offset some of that, but those options have been already pushed far. Recycling uses significantly less energy than primary production, and recycling is one of the ways to reduce energy use per ton further, and for a time, an offsetting decline in mining extraction.

It is likely that the willingness to pay more and more will fade and the demand will go down. Exhaustion does not always mean that the resource runs empty, it means that the 


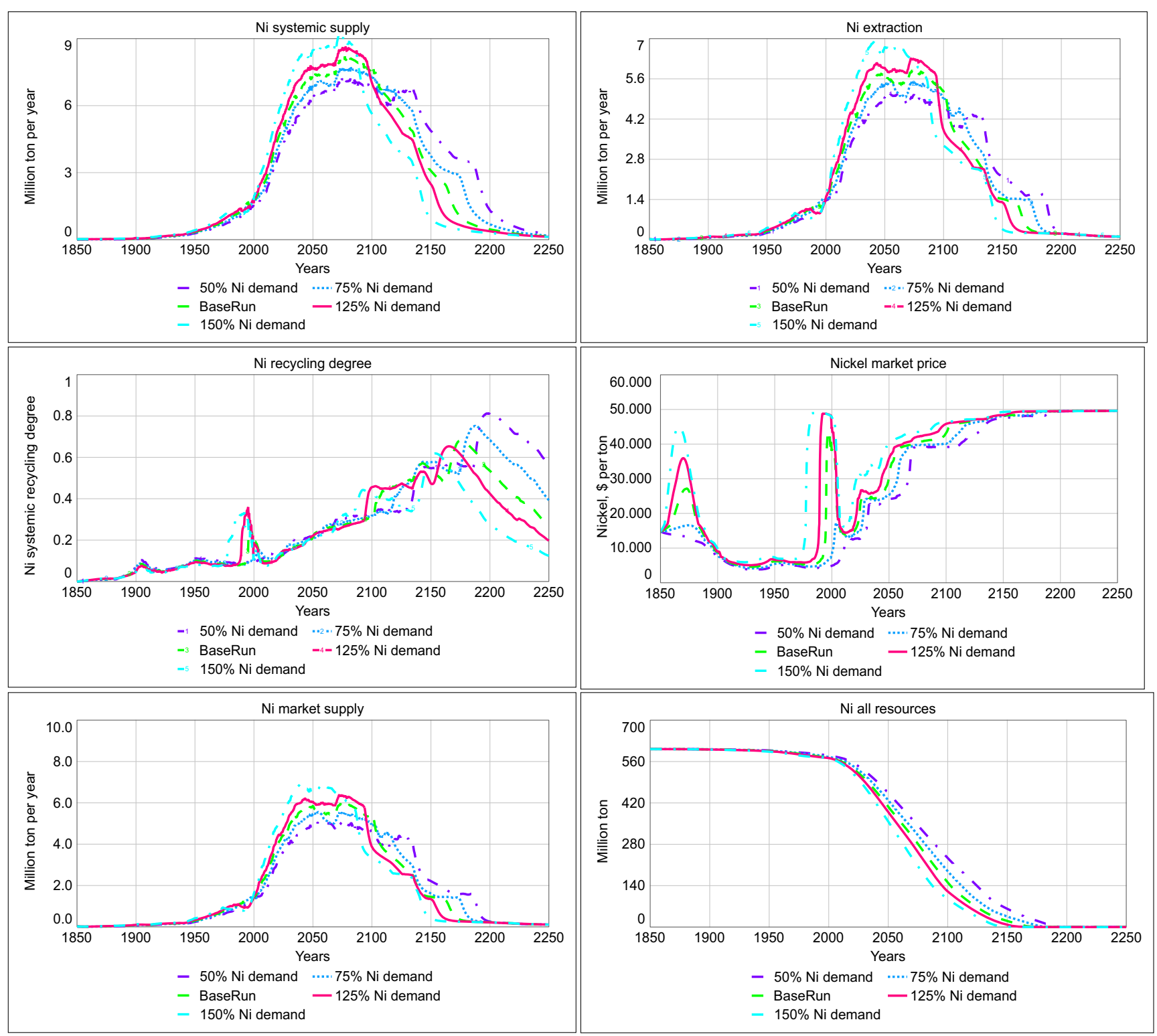

Fig. 14 S2: A sensitivity run varying nickel demand, first run is $50 \%$ of the demand in the base run, and then incremental step change of $25 \%$, last run with $150 \%$ demand compared to the base run. See Table 6

extraction stops because the cost of extraction has become more extensive than the befit of the product

\section{Conclusions}

Returning to the initial questions, based on the simulation outputs presented, we conclude:

1. Sustainability of nickel supply: There are more nickel resources available for extraction than earlier assumed, but the main conclusions are still that nickel is a resource that may run empty in the future. The amount of nickel turned out to be exhaustible, under all scenarios tried. When the best ore qualities have been extracted, then the extraction will become more and more challenging, both in terms of physical effort and in terms of cost for extraction.

- Based on the Base run: nickel will become physically limited under the Base run scenario. Even though the extractable resources of nickel might be substantially larger than earlier anticipated, it can be seen that they are not large enough to last indefinitely at any rate of extraction. At present rates of extraction, the available nickel resources may go empty within a century. According to the results, nickel will run out in 2190; after that, only small amounts of secondary extraction and recycling will be available sources. 

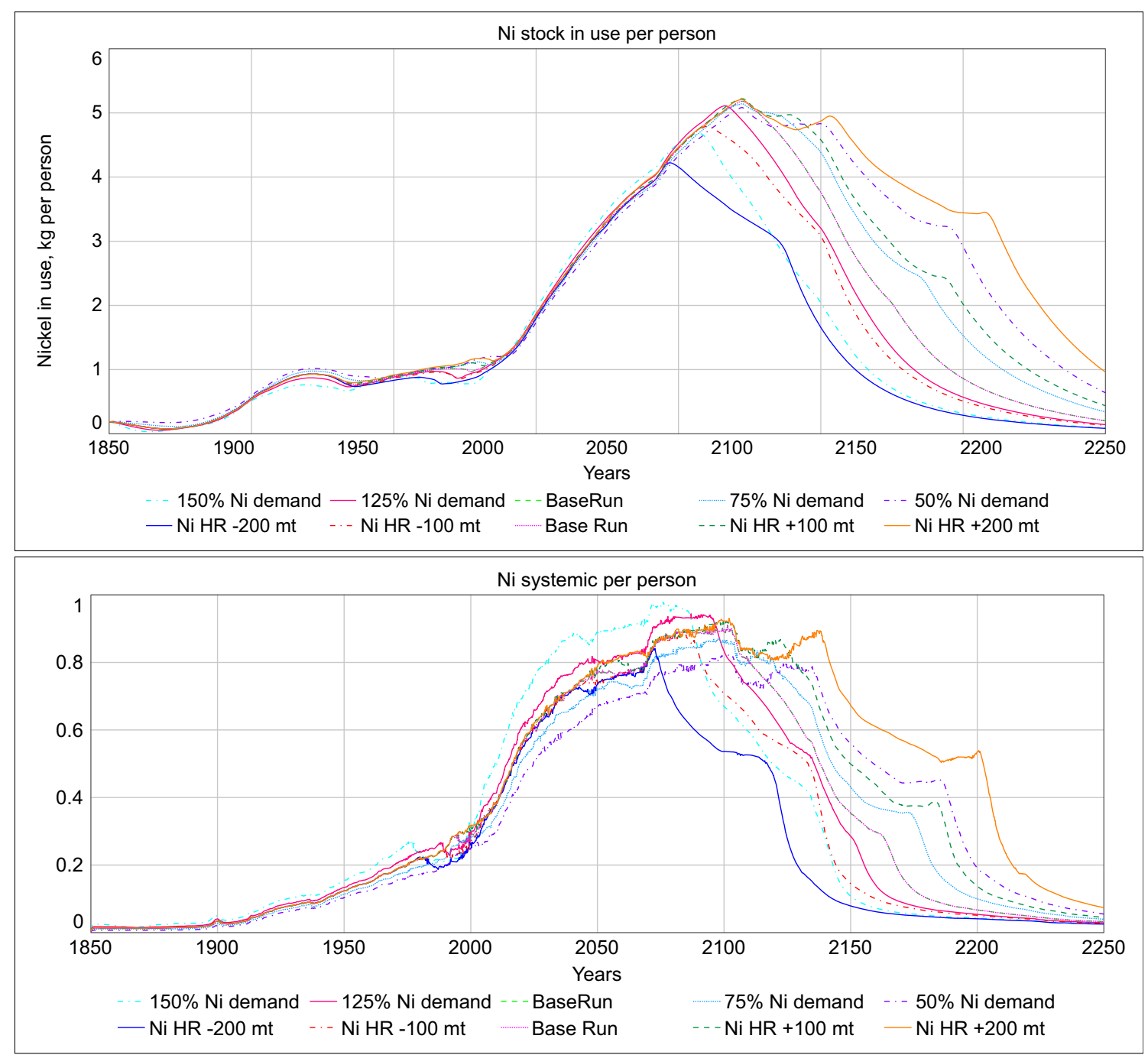

Fig. $15 \mathrm{~S} 1$ : supply per person and year for nickel ( $\mathrm{kg} /$ person and year) and stock-in-use per person ( $\mathrm{kg} /$ person) for nickel based on S1 runs

- Based on variations in initial resource size and demand: Varying the nickel resource size and demand will change the shape of the curves and shift the timing. However, the outcome stays the same. The sensitivity analysis shows that finding an extra 200 million ton will only postpone the decline by several decades.

- The supply per person per year: Nickel supply per capita per year reaches a maximum around 2100 . After 2190, nickel runs out (Fig. 11b and f). Hard scarcity is very likely for nickel in the future. Nickel will be in soft scarcity, and in several of the scenarios, hard scarcity may occur (Fig. 11b).

2. The price evolution: The scarcity for nickel is both because of lack of extractable metal, and because of a trend towards less quality ore that will cause the metal price to increase as extraction costs increase with lower ore quality. The price will continue to go up as a result of continued declining ore grades and increased costs of extraction after 2050 (Fig. 10c)

The present way of using nickel is unsustainable; the recycling is too low at present. Without active measures beyond the effect of price alone, the recycling stays low until scarcity has driven up the price. Then too much nickel will already have been lost. The scarcity risk can be partly mitigated by improving recycling, improved product design for recyclability, manufacturing efficiency, better use efficiency and lean product design as shown by the sensitivity analysis. With increased price because of soft or hard scarcity, recycling is expected to go up and soften the scarcity somewhat.

The assessment shows that nickel will become a limiting resource for making stainless steel. It is noted that the peak and decline in nickel supply will affect the trajectory for stainless steel strongly, and when the nickel price rises, so will the price of stainless steel go up. For this see our work on stainless steel [49] 
Supplementary Information The online version contains supplementary material available at https://doi.org/10.1007/s42461-020-00370-y.

Acknowledgments Open Access funding provided by Inland Norway University Of Applied Sciences. This study contributed to the SimRess project (Models, potential and long-term scenarios for resource efficiency), funded by the German Federal Ministry for Environment and the German Environmental Protection Agency (FKZ 371293 102). Dr. Ullrich Lorenz is a project officer at the German Environmental Protection Agency (UBA) at Dessau. This study contributed to the EU H2020 LOCOMOTION Project. The project coordinator is Luis Javier Miguel Gonzales at Valladolid University, Valladolid, Spain.

Authors' Contributions Both authors contributed significantly to the development of the WORLD7 model, the development of the nickel module, in doing the simulations and in writing the paper in close cooperation.

\section{Compliance with Ethical Standards}

Conflict of Interest The authors declare that they have no conflict of interest.

Open Access This article is licensed under a Creative Commons Attribution 4.0 International License, which permits use, sharing, adaptation, distribution and reproduction in any medium or format, as long as you give appropriate credit to the original author(s) and the source, provide a link to the Creative Commons licence, and indicate if changes were made. The images or other third party material in this article are included in the article's Creative Commons licence, unless indicated otherwise in a credit line to the material. If material is not included in the article's Creative Commons licence and your intended use is not permitted by statutory regulation or exceeds the permitted use, you will need to obtain permission directly from the copyright holder. To view a copy of this licence, visit http://creativecommons.org/licenses/by/4.0/.

\section{References}

1. Meadows DH, Meadows DL, Randers J, Behrens W (1972) Limits to growth. Universe Books, Virginia

2. Meadows DH, Meadows DL, Randers J (1992) Beyond the Limits: confronting global collapse, envisioning a sustainable future. Chelsea Green Publishing Company, Hartford

3. Meadows DH, Randers J, Meadows D (2005) Limits to growth. The 30-year update. Universe Press, New York

4. R Heinberg (2001) Peak Everything: waking Up to the Century of Decline in Earth's Resources. Clairview

5. Bardi U (2013) Extracted. How the quest for mineral wealth is plundering the planet. The past, present and future of global mineral depletion. A report to the Club of Rome. Chelsa Green Publishing, Vermont

6. Graedel TES, Buckert M, Reck BK (2011) Assessing mineral resources in society. Metal stocks and recycling rates. UNEP, Paris

7. Sverdrup H, Ragnarsdottir KV (2014) Natural Resources in a planetary perspective. European Geochemical Society. Geochem Perspect 2:129-341

8. Nuss P, Harper EM, Nassar NT, Reck BK, Graedel TE (2014) Criticality of Iron and its principal alloying elements. Environ Sci Technol 48:4171-4177

9. D Stanway (2014) China steel output near peak, say executives, in bad news for miners. [Online]. Available: http://www.reuters.com/ article/2014/03/06/china-parliament-steelidUSL3N0LT13W20140306.

10. Daigo I, Matsuno Y, Adachi Y (2010) Substance flow analysis of chromium and Nickel in the material flow of stainless steel in Japan. Resour Conserv Recycl 54:851-863

11. Alexandrova A, Northcott R (2013) It's just a feeling: why economic models do not explain. J Econ Methodol 20:262-267

12. Bookstaber R (2017) The End of Theory: financial crises, the failure of economics and the sweep of human interaction. Princeton University Press, Princeton

13. D. Colander et al. (2009) The financial crisis and the systemic failure of academic economics, Univ. of Copenhagen Dept. of Economics Discussion

14. Eichner AS, Kregel JA (1975) An essay on Post-Keynesian Theory: a new paradigm in economics. J Econ Lit 13:1293-1314

15. Hall C, Lindenberger D, Kummel R, Kroeger T, Eichhorn W (2001) The need to reintegrate the natural sciences with economics. Bioscience 51:663-667

16. Seppelt R, Manceur AM, Liu J, Fenichel EP, Klotz S (2014) Synchronized peak-rate years of global resources use. Ecol Soc 19:50-64

17. Giljum S, Hubacek K (2009) Conceptual foundations and applications of physical input-output tables. In: Suh S (ed) Handbook of input-output economics in industrial ecology. Springer, Dordrecht, the Netherlands, pp 61-75

18. Giljum S, Hinterberger F, Lutz C, Meyer B (2008) No Title. In: Suh $\mathrm{S}$ (ed) Handbook of input-output economics for industrial ecology. Springer, Dordrecht, Netherlands

19. Forrester J (1971) World dynamics. Pegasus Communications, Waltham MA

20. Senge P (1990) The Fifth Discipline. The Art and Practice of the Learning Organisation. Century Business, New York

21. Sverdrup H (2018) In: Haraldsson H, Olafsdottir AH, Belyazid S, Svensson M (eds) System thinking, system analysis and system dynamics: find out how the world works and then simulate what would happen., 3rd revise. Háskolaprent, Reeykjavik

22. Sterman J (2000) Business Dynamics : Systems Thinking and Modeling for a Complex World. Irwin/McGraw-Hill, United States of America

23. Sverdrup H, Koca D (2018) The WORLD Model Development and The Integrated Assessment of the Global Natural Resources Supply. Verlag Umweltbundesamt, Berlin

24. U. Lorenz, H. U. Sverdrup, K. V Ragnarsdottir, and H. Lehmann, "Global megatrends and resource use - a systemic reflection.," in Factor X; Challenges, implementation strategies and examples for a sustainable use of natural resources, M. Hinzmann, N. Evans, T. Kafyke, S. Bell, M. Hirschnitz-Garbers, and E. M., Eds. Springer, Berlin, 2017, pp. 31-44.

25. Sverdrup HU, Olafsdottir AH, Ragnarsdottir KV, Koca D (2018) A System dynamics assessment of the supply of molybdenum and rhenium used for super-alloys and specialty steels, using the WORLD6 model. Biophys Econ Resour Qual 3:7

26. Sverdrup KV, Ragnarsdottir H (2016) The future of platinum group metal supply; an integrated dynamic modelling for platinum group metal supply, reserves, stocks-in-use, market price and sustainability. Resour Conserv Recycl 114:130-152

27. Nuss P, Eckelman MJ (2014) Life cycle assessment of metals: a scientific synthesis. PLoS One

28. Sverdrup H, Svensson M (2002) Defining sustainability. In: Developing principles for sustainable forestry, Results from a research program in southern Sweden. In: Sverdrup H, Stjernquist I (eds) Managing Forest Ecosystems, vol 5. Kluwer Academic Publishers, Amsterdam, pp 21-32

29. Sverdrup KV, Olafsdottir H, Ragnarsdottir AH (2019) Assessing global copper, zinc and lead extraction rates, supply, price and 
resources using the WORLD6 integrated assessment model. Resour Conserv Recycl X4 100007:1-26

30. Sverdrup H, Ragnarsdottir KV (2016) Modelling the global primary extraction, supply, price and depletion of the extractable geological resources using the COBALT model. Biophys Econ Resour Qual

31. Ataei M, Osanloo M (2003) Determination of optimum cut-off grades of multiple metal deposits by using the Golden Section search method. J South Afr Inst Min Metall 103:493-499

32. Sverdrup D, Olofsdottir H, Ragnarsdottir AH, Koca KV (2018) A system dynamics assessment of the supply of molybdenum and rhenium used for superalloys and specialty steels, using the WORLD6 model. Biophys Econ Resour Qual 4:1-52

33. Gerst M (2008) Revisiting the cumulative grade-tonnage relationship for major copper ore types. Econ Geol:615-628

34. Gerst M (2009) Linking material flow analysis and resource policy via future scenarios of in-use stock: an example for copper. Environ Sci Technol 43:6320-6325

35. House HJ, Baclig KZ, Ranjan AC, van Nierop M, Wilcox EA, Herzog J (2011) Economic and energetic analysis of capturing $\mathrm{CO} 2$ from ambient air. In: Proceedings of the National Academy of Science, pp 20428-20433

36. National Archives of the United States (1995) US Bureau of Mines 1932-1995

37. National Minerals Information Center (2017). US Geological Survey Minerals Yearbook (1932-2017)

38. U. S. G. S. USGS. Minerals Commodity Summaries, 1999, 2002 , 2005, 2006, 2007, 2008, 2011, 2012, 2013, 2014, 2015, 2016, 2017

39. Olafsdottir AH, Sverdrup HU, Ragnarsdottir KV (2017) On the metal contents of ocean floor nodules, crusts and massive sulphides and a preliminary assessment of the extractable amounts. In: Ludwig C, Valdivia S (eds) World resources Forum 2017. Villigen PSI and World Resources Forum, St. Gallen, Switzerland, pp 150-156

40. (2017) A system dynamics assessment of supply sufficiency for aerospace technology needs using WORLD6. In: World Resources Forum 2017

41. Sverdrup H, Olafsdottir AH (2019) Conceptualization and parameterization of the market price mechanism in the WORLD6 model for metals, materials and fossil fuels. Miner Econ 2019:31

42. Sverdrup HU, Olafsdottir AH, Ragnarsdottir KV, Koca D (2018) A system dynamics assessment of the supply of molybdenum and rhenium used for super-alloys and specialty steels, using the WORLD6 model. Biophys Econ Resour Qual 3(3):7
43. Sverdrup HU, Olafsdottir AH, Ragnarsdottir KV, Koca D, Lorenz U (2019) The WORLD6 integrated system dynamics model: examples of results from simulations. In: Ludwig C, Valdivia S (eds) Progress towards the Resource Revolution. Villigen PSI and World Resources Forum, St. Gallen, Switzerland, pp 67-78

44. Olafsdottir AH, Sverdrup HU (2018) Modelling global mining, secondary extraction, supply, stocks-in-society, recycling, market price and resources, using the WORLD6 model; Tin. Biophys Econ Resour Qual 3(3):11

45. Mudd GM (2009) Historical trends in base metal mining: backcasting to understand the sustainability of mining. In: Proceedings of the 48th Annual Conference of Metallurgists no. August Issue

46. Sverdrup H, Koca D, Ragnarsdottir KV (2017) Defining a free market: drivers of unsustainability as illustrated with an example of shrimp farming in the mangrove forest in South East Asia. J Clean Prod 140:299-311

47. Sverdrup HU, Olafsdottir AH, Ragnarsdottir KV (2017) Modelling global wolfram mining, secondary extraction, supply, stocks-in-society, recycling, market price and resources, using the WORLD6 System dynamics model. Biophys Econ Resour Qual 2(3):11

48. Sverdrup HU, Olafsdottir AH (2018) A system dynamics model assessment of the supply of niobium and tantalum using the WORLD6 model. Biophys Econ Resour Qual 3:5

49. Sverdrup H, Koca D, Ragnarsdottir KV (2013) Peak metals, minerals, energy, wealth, food and population; urgent policy considerations for a sustainable society. J Env Sci Eng 5:499-534

50. LBMA (2018) LBMA Palladium price discovery process explained. LBMA, London

51. LBMA (2018) LBMA platinum and palladium prices price discovery process schedule. LBMA, London

52. Mudd G, Jowitt S (2014) Detailed assessment of global Nickel resource trends and endowments database. Econ Geol

53. Sverdrup HU, Olafsdottir AH (2019) Assessing the Long-Term Global Sustainability of the Production and Supply for Stainless Steel. Biophys Econ Resour Qual 4(2):8

54. Sverdrup HU, Ragnarsdottir KV, Koca D (2017) An assessment of global metal supply sustainability: global recoverable reserves, mining rates, stocks-in-use, recycling rates, reserve sizes and time to production peak leading to subsequent metal scarcity. J Clean Prod 140:359-372

Publisher's Note Springer Nature remains neutral with regard to jurisdictional claims in published maps and institutional affiliations. 